\title{
SinOPSIS DE LAS ESPECIES DEL GÉNERO BACOPA (Plantaginaceae, Gratioleae) de Paraguay y sus ESTADOS DE CONSERVACIÓN
}

\author{
A synopsis of the species of the genus Bacopa (Plantaginaceae,

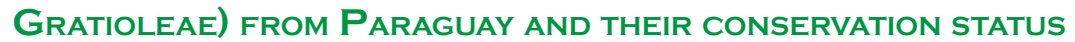

María de las Mercedes Sosa ${ }^{1 *}\left(\mathbb{D}\right.$, Javier E. Florentín ${ }^{1}$ y y André V. Scatigna ${ }^{2}$ (D)

1. Instituto de Botánica del Nordeste (UNNE-CONICET), Sargento Cabral 2131 y FACENAUNNE, Av. Libertad 5460, 3400 Corrientes, Argentina

2. Centro de Educação, Ciências Exatas e Naturais, Departamento de Biologia, Universidade Estadual do Maranhão, Cidade Universitária Paulo VI, s/n, 65054-970, São Luís, Maranhão, Brasil.

*mdlmsvg@yahoo.com.ar

Citar este artículo

SOSA, M. DE LAS M., J. E. FLORENTÍN \& A. V. SCATIGNA. 2021. Sinopsis de las especies del género Bacopa (Plantaginaceae, Gratioleae) de Paraguay y sus estados de conservación. Bol. Soc. Argent. Bot. 56: 217-242.

DOI: https://doi. org/10.31055/1851.2372.v56. n2.30943

Recibido: 17 Nov 2020

Aceptado: 24 Abr 2021

Publicado en línea: 10 Jun 2021

Publicado impreso: 30 Jun 2021

Editor: Diego Gutiérrez

ISSN versión impresa 0373-580X

ISSN versión on-line 1851-2372

\section{SUMMARY}

Background and aims: Bacopa (Plantaginaceae) represents the genus with the largest number of species in the Gratioleae tribe, occupying a great diversity of humid environments in South America. The objective of this study is to contribute to the morphological and taxonomic knowledge of Bacopa from Paraguay, providing an identification key for the accepted taxa, morphological descriptions, botanical illustrations, distribution maps, observations and conservation status to country level.

M\&M: The data obtained is based on fieldwork to Paraguay and examination of herbarium specimens. The conservation status of the species was evaluated in Paraguay taking its distributions into account (criterion B), according to the IUCN guidelines.

Results \& Conclusions: Fifteen species and two varieties are recorded from Paraguay. Bacopa australis and B. stricta are cited for the first time in the country. Preliminarily conservation status of the species and Paraguayan distribution assessments are presented. Of the 15 species confirmed from Paraguay, 13 are under a threatened category, 12 are endangered (EN), and $B$. verticillata in critically endangered (CR). The species are distributed in five ecoregions and the largest number of species (12) is found in the Humid Chaco region.

\section{KEY WORDS}

Bacopa, conservation status, Gratioleae, Paraguay, taxonomy.

\section{RESUMEN}

Introducción y objetivos: Bacopa (Plantaginaceae) representa el género con mayor número de especies de la tribu Gratioleae, ocupando una gran diversidad de ambientes húmedos en Sudamérica. El objetivo de este estudio es contribuir al conocimiento morfológico y taxonómico de las especies de Bacopa de Paraguay, aportando una clave de identificación para los taxones aceptados, descripciones morfológicas, ilustraciones botánicas, mapas de distribución, observaciones y estado de conservación a nivel de país.

M\&M: Los datos obtenidos se basan en el trabajo de campo y el examen de especímenes de herbario. El estado de conservación de las especies se evaluó en Paraguay, teniendo en cuenta sus distribuciones (criterio B), de acuerdo con las directrices de la UICN.

Resultados/Conclusiones: Se registran para Paraguay 15 especies de Bacopa, una con dos variedades. Se citan los primeros registros de Bacopa australis y $B$. stricta para el país. Se presentan preliminarmente los estados de conservación de las especies y evaluaciones de distribución paraguaya. De los 15 taxones confirmados para Paraguay, 13 se encuentran con categoría de amenaza, 12 están en peligro (EN) y $B$. verticillata en peligro crítico $(C R)$. Las especies se distribuyen en cinco ecorregiones, de las cuales el mayor número de especies (12) se encuentra en la región del Chaco Húmedo.

\section{Palabras clave}

Bacopa, estado de conservación, Gratioleae, Paraguay, taxonomía. 


\section{INTRODUCCIÓN}

El género Bacopa Aubl. (Plantaginaceae) posee el mayor número de especies (unas 50-60) dentro de la tribu Gratioleae. Dicha tribu, anteriormente dentro de Scrophulariaceae, actualmente se considera parte de Plantaginaceae sobre la base de estudios de filogenia molecular (Albach et al., 2005). Bacopa es un género morfológicamente muy heterogéneo y está constituido por especies distribuidas en áreas tropicales y subtropicales de todo el mundo, siendo la mayoría de ellas nativas de América (Souza \& Giulietti, 2009; Sosa et al., 2018), fundamentalmente en humedales neotropicales como el Pantanal Matogrossense del sudoeste de Brasil (Pott \& Pott, 1997; Pott et al., 2011). Comprende hierbas acuáticas emergentes (por ejemplo, Bacopa australis V.C. Souza y B. verticillata (Pennell \& Gleason) Pennell) y hierbas palustres erectas (por ejemplo, $B$. congesta Chodat \& Hassl.).

Sosa et al. (2018) destacaron la historia taxonómica compleja de Bacopa ya que autores como Pennell (1946), D’Arcy (1979), Souza \& Giulietti (2009) describieron varios géneros que actualmente se reconocen como sus sinónimos. Es de destacar que Scatigna et al. (2018) sugirieron que este género constituye un grupo parafilético por lo que estudios adicionales para una delimitación más precisa son necesarios. Bacopa se reconoce taxonómicamente por características tales como el cáliz con sépalos fuertemente desiguales (i.e., uno dorsal, dos laterales desarrollados y dos internos lineares) y anteras con dos tecas fértiles sésiles, no separadas por un conectivo muy desarrollado y es afín en su morfología a Mecardonia Ruiz \& Pav.

Algunas especies se utilizan medicinalmente como es el caso de Bacopa monnieri (L.) Wettst. con propiedades antiinflamatorias, analgésicas, antipiréticas, sedantes y antiepilépticas, así como para aliviar la ansiedad, depresión y trastornos sistémicos como cardiovasculares, gastrointestinales, hepáticos, problemas neurológicos y respiratorios (Vohora et al., 1997; Russo \& Borrelli, 2005; Souza \& Felfili, 2006; Dhanasekaran et al., 2007; Charoenphon et al., 2016). Por otra parte, Bacopa australis posee valor ornamental siendo utilizada en acuarios por formar un elegante y decorativo cojín verde, y está siendo objeto de estudios biotecnológicos actualmente para su micropropagación en cultivos in vitro (Nugraha et al., 2017; Yunita et al., 2018).
Paraguay tiene una superficie total de 406.752 $\mathrm{km}^{2}$ y se encuentra dividido por el Río Paraguay en dos regiones: Oriental y Occidental. Entre el $25-30 \%$ la superficie del país está cubierta por humedales y se observa una gran diversidad específica tanto animal como vegetal, concentrada principalmente en la región Oriental (Mereles, 2007; De Egea et al., 2016; Ávila, 2018). Esta región es la más húmeda, con numerosos cursos de agua y sistemas lacustres bastante complejos, algunos aún poco conocidos, como el complejo Ypoá en los límites de los departamentos Central y Paraguarí, el estero de Milagros en el departamento de San Pedro y la gran mayoría de los humedales del departamento de Ñeembucú, y el lago Ypacaraí en los departamentos Central y Cordillera (Mereles et al., 2015). La región Oriental ha sufrido una intensa degradación del hábitat en los últimos 70 años, identificándose como las principales causas de modificación del hábitat la industria de la madera, el establecimiento de nuevos asentamientos humanos y la deforestación para la agricultura (Fleytas, 2007; Gauto et al., 2011).

El trabajo tiene como objetivo contribuir al conocimiento taxonómico, morfológico y de conservación de las especies de Bacopa que habitan en Paraguay, para lo cual se confeccionó una clave de identificación para los taxones aceptados, se describió morfológicamente a las especies, se confeccionaron ilustraciones, se elaboraron mapas de distribución geográfica y se analizó el estado de conservación de cada una de las especies para el país.

\section{Materiales y Métodos}

\section{Morfología y taxonomía}

Para el tratamiento taxonómico se analizaron e identificaron 324 especímenes de los siguientes herbarios: AS, B, BA, BAB, BM, C, CORD, CTES, CTESN, G, FCQ, K, LIL, M, MO, P, NY y SI (Thiers, 2020) mediante el estudio directo de los materiales o de imágenes digitales provenientes de bases de datos de plantas globales como JSTOR (ITHAKA, 2020).

Se realizaron salidas de campo en marzo del 2018 en los departamentos de Paraguay de Alto Paraná, Amambay, Caaguazú, Canindeyú, Central, Concepción, Cordillera, Guairá, Paraguarí y San 


\section{M. de las M. Sosa et al. - Bacopa (Plantaginaceae) de Paraguay y conservación}

Pedro. Las especies fueron estudiadas en el campo y los ejemplares recolectados se depositaron en los herbarios AS, CTES y FCQ. Muestras vegetales fueron conservadas y fijadas en FAA y las estructuras reproductivas de ejemplares de herbario se rehidrataron hirviéndolas con agua para el análisis morfológico con microscopio estereoscópico Wild M5. Se ilustraron los caracteres con valor taxonómico.

\section{Distribución y estado de conservación}

Para el análisis de la distribución de especies se utilizó material de los herbarios citados y de las colectas.

Los especímenes fueron georreferenciados, en caso de no contar con las coordenadas en las etiquetas de herbario, se usó Google Earth Pro (2018) versión 7.3.2 para georreferenciar los especímenes y luego fueron analizados por medio del programa DIVA-GIS (Hijmans, 2015). El estado preliminar de conservación de cada especie se evaluó teniendo en cuenta solo el criterio B y las directrices para su uso de la lista roja de la UICN (Unión Internacional para la Conservación de la Naturaleza) a nivel regional y nacional (IUCN, 2017) versión 13. Las especies fueron evaluadas utilizando GeoCAT (Geospatial Conservation Assessment Tool, Bachman et al., 2011, disponible en http://geocat. kew.org), calculándose la extensión de ocurrencia (EOO) y el área de ocupación (AOO) para cada especie, con un tamaño de cuadrícula de ca. $2 \mathrm{~km}$ (área de celda de $4 \mathrm{~km}^{2}$ ).

Para la distribución geográfica de las especies se sigue el criterio de Ecorregiones del Paraguay establecidas por Clay et al. (2005).

\section{Resultados y Discusión}

Como resultado del trabajo se reconocen 15 especies de Bacopa para Paraguay (Tabla 1). Se destaca que Bacopa australis y $B$. stricta son registrados en este trabajo por primera vez para este país.

\section{Tratamiento taxonómico}

Bacopa Aubl., J. B. C. F. Aublet, Hist. Pl. Guiane 1: 128-130, pl. 49. 1775.

TIPO: Bacopa aquatica Aubl.

Monniera P. Browne, Civ. Nat. Hist. Jamaica 269. 1756, nom. rejic.
Bramia Lam. Encycl. 1: 459. 1783.

Herpestis C. F. Gaertn., Fruct. \& Sem. pl. 3: 186. 1807.

Ranaria Cham., Linnaea 8: 30. 1833.

Monocardia Pennell, Proc. Acad. Nat. Sci. Philadelphia 72: 155. 1920.

Hierbas erectas o rastreras, anuales o perennes, glabras o pubescentes. Hojas simples, opuestas, raro verticiladas, sésiles, raro pecioladas, enteras, raro divididas, pinnatisectas o pinnatífidas, linearlanceoladas, lanceoladas, elípticas, ovadas, orbiculares, obovadas u oblongas, espatuladas, margen entero o aserrado, glabras o pubescentes. Flores axilares, solitarias, 2-4 por axila o dispuestas en inflorescencias racimosas terminales, sésiles o pediceladas. Bractéolas 2 insertas por debajo de la base del cáliz, o ausentes. Cáliz dialisépalo, con 5 sépalos, imbricados, desiguales, un sépalo dorsal, dos laterales y dos internos más pequeños. Corola pentámera, tubular, blanca, violeta, azul, a veces anaranjada o roja; limbo patente o conspicuamente bilabiado, con labio superior bilobulado, y labio inferior trilobulado. Estambres 4, raro $5(B$. aquatica) o 2 (B. repens), didínamos, raro de igual longitud; anteras libres, tecas paralelas. Ovario 2-carpelar, bilocular, pluriovulado, glabro, a veces rodeado por un círculo de cerdas; estilo entero o dividido; estigma dilatado, capitado o bilobulado. Fruto cápsula ovoide o globosa, con 2 ranuras longitudinales, de 4 valvas, con ápice agudo o redondeado. Semillas numerosas, diminutas, ovoides, elipsoides, reticuladas.

Distribución. Bacopa tiene una distribución Pantropical con la mayor diversidad de especies en el Neotrópico, especialmente en las regiones cálidas de América del Sur en humedales del Pantanal Matogrossense en Brasil y el Iberá correntino en Argentina (Pott et al., 2011; Sosa et al., 2018). En Paraguay se reconocen en este trabajo 15 especies nativas de Bacopa, siendo el género con mayor número de representantes de la tribu Gratioleae en este país. Además, cabe destacar que en Brasil se han registrado 26 especies (Souza \& Giulietti, 2009; Souza, 2020) y en Argentina 12 (Sosa et al., 2018) lo que junto con las 15 para Paraguay determina que Bacopa es el género con mayor número de representantes dentro de la tribu Gratioleae para la región. 


\section{Clave de identificación de las especies de Bacopa de Paraguay}

1. Hojas 2-3 veces más largas que anchas. Bractéolas 2. Sépalo dorsal con base aguda o redondeada.

2. Hojas 3-5 verticiladas, dimórficas, las sumergidas pinnatisectas o pinnatífidas, las aéreas pinnatífidas u ovadas. B. verticillata

$2 '$. Hojas opuestas, no dimórficas, todas enteras.

3. Hierbas glabras.

4. Hojas linear-lanceoladas. Sépalo dorsal lanceolado.

B. gratioloides

4'. Hojas espatuladas. Sépalo dorsal ovado.

B. monnieri

3'. Hierbas pubérulas o híspido-estrigosas.

5. Flores dispuestas en racimos terminales, rojas, naranjas o rosas.

B. congesta

5'. Flores axilares, 2-4 por axila, blancas, azules o lilas.

6. Flores blancas con pedicelos de 0,5-1,2 mm long.

B. axillaris

6'. Flores azules o lilas con pedicelos de 4-20 $\mathrm{mm}$ long.

7. Hierbas de $5-30 \mathrm{~cm}$ de altura. Corola glabra.

B. monnierioides

7'. Hierbas de $35-80 \mathrm{~cm}$ de altura. Corola pubescente.

8. Hojas sésiles.

9. Hojas oblongas o angostamente ovadas de base auriculada, margen entero o ligeramente aserrado en la parte distal.

B. paraguariensis

9'. Hojas ovado-lanceoladas u ovadas de base aguda o redondeada, margen aserrado. ....

B. scabra

8 '. Hojas pecioladas.

B. stricta

1'. Hojas tan largas como anchas. Bractéolas ausentes (a excepción de $B$. serpyllifolia). Sépalo dorsal con base cordada o subcordada.

10. Corola pubescente. Ovario con un círculo de cerdas alrededor de la base.

B. serpyllifolia

10'. Corola glabra. Ovario sin círculo de cerdas alrededor de la base.

11. Tallos híspido-vellosos. Estilo entero.

B. salzmannii

11'. Tallos estrigosos o subglabros. Estilo dividido.

12. Estambres 2. Pedicelos florales de $5 \mathrm{~mm}$ long.

B. repens

12 '. Estambres 4. Pedicelos florales de $10 \mathrm{~mm}$ long.

13. Cáliz glabro.

B. rotundifolia

13'. Cáliz pubérulo.

14. Corola de 8-10 mm long., el doble del cáliz.

B. dubia

14'. Corola de 3-5 mm long., apenas sobresaliendo del cáliz.

B. australis

1. Bacopa australis V. C. Souza, Acta Bot. Bras. 15: 58. 2001. TIPO: BRASIL. Paraná, Capanema, Río Iguazú, 23-XII-1966, J. Lindeman \& H. Haas 3358 (Holotipo, MBM!, isotipos K!, NY 00499316!, UB 167026, US 2631536).

Hierbas acuáticas, de $5-15 \mathrm{~cm}$ de altura, estrigosas. Tallos rastreros, algunos ascendentes, estrigosos. Hojas opuestas, sésiles, orbiculares o suborbiculares, raro oval-elípticas, 4-10 x 3-9 $\mathrm{mm}$, ápice y base redondeados, margen entero, con base y nervaduras densamente pubescentes. Flores axilares, solitarias, pedicelos hasta 50 mm long., subglabros; sin bractéolas. Cáliz con 5 sépalos, uno dorsal oval de base cordada o subcordada, dos laterales ovales de base cordada 
Tabla 1. Especies de Bacopa registradas para Paraguay con su distribución de acuerdo a las ecorregiones (Clay et al., 2005). Se marcan con asterisco $\left(^{*}\right)$ las especies citadas por primera vez.

\begin{tabular}{|c|c|c|c|c|c|}
\hline \multirow[b]{2}{*}{ Especies } & \multicolumn{5}{|c|}{ Ecorregiones de Paraguay } \\
\hline & $\begin{array}{l}\text { Bosque Atlántico } \\
\text { del Alto Paraná }\end{array}$ & Cerrado & Chaco Húmedo & $\begin{array}{l}\text { Chaco } \\
\text { Seco }\end{array}$ & $\begin{array}{c}\text { Pastizales } \\
\text { Mesopotámicos }\end{array}$ \\
\hline B. australis* & $x$ & & $x$ & & \\
\hline B. axillaris & & $x$ & $x$ & & \\
\hline B. congesta & $x$ & $x$ & $x$ & & $x$ \\
\hline B. dubia & $x$ & & $x$ & & $x$ \\
\hline B. gratioloides & & $x$ & $x$ & & \\
\hline B. monnieri & & & $x$ & $x$ & \\
\hline B. monnierioides & $x$ & & $x$ & & \\
\hline B. paraguariensis & $x$ & & & & \\
\hline B. repens & & & $x$ & & \\
\hline B. rotundifolia & & & $x$ & & \\
\hline B. salzmannii & $x$ & $x$ & $x$ & & \\
\hline B. scabra var. scabra & $x$ & & & & \\
\hline B. scabra var. laxiflora & $x$ & $x$ & & & \\
\hline B. serpyllifolia & $x$ & & $x$ & & \\
\hline B. stricta* & & & $x$ & & \\
\hline B. verticillata & $x$ & & & & \\
\hline Total por ecorregiones & 10 & 5 & 12 & 1 & 2 \\
\hline
\end{tabular}

o subcordada y dos internos linear-lanceolados, con tricomas en el ápice, en la nervadura central y bordes. Corola de 3-5 mm long., blanca o celeste, glabra. Estambres 4, didínamos. Ovario ovoide, estilo bifurcado en la parte terminal. Cápsula ovoide, ápice agudo.

Iconografias. Souza 2001: 59; Sosa et al., 2018: 4, fig. 1.

Distribución geográfica y hábitat. Especie exclusiva de América del Sur, crece en pastizales inundables del sur de Brasil (Mato Grosso do Sul, Paraná, Rio Grande do Sul, Santa Catarina) y nordeste de Argentina (Corrientes), hasta los 500 msnm. En este trabajo, se cita por primera vez para el centro de Paraguay (Dptos. Cordillera y San Pedro) donde habita en zonas húmedas, a orillas de lagunas o lagos, en esteros, o arroyos del Chaco Húmedo y Bosque Atlántico del Alto Paraná.
Estado de conservación en Paraguay. De acuerdo con la extensión de ocurrencia (EOO) estimada en $786 \mathrm{~km}^{2}$ y al área de ocupación (AOO) estimada en $16 \mathrm{~km}^{2}$, la especie debe ser considerada como en peligro de extinción (EN), según el criterio B: solo se registraron tres poblaciones de $B$. australis, todas restringidas a la parte Oriental del Paraguay, en los departamentos de Cordillera y San Pedro, en donde se ha observado un continuo declive en el área y en la calidad del hábitat adecuado para esta especie. Esto se debe principalmente al drenaje antrópico de los lagos para actividades agrícolas y ganaderas, colmatación de los cauces de agua, que lleva a la pérdida de cobertura vegetal autóctona y la invasión de especies exóticas, sumado a la continua contaminación de los cuerpos de agua y la intensa deforestación existente en las partes más altas que rodean al espejo de agua (Mereles et al., 1992, 2006, 2007; Fleytas, 2007). Teniendo en cuenta todo lo anterior se la categoriza de forma preliminar como: EN B1b (ii, iii, iv) + 2b (ii, iii). 
Material examinado. PARAGUAY. Dpto. Cordillera: San Bernardino, Rojas 14305 (LIL); ídem, I-1983, Mereles 142 (CTES). Dpto. San Pedro: San Miguel Compañía Sargento Loma, IV1992, Basualdo 4108 (FCQ).

Observaciones. Bacopa australis crece fácilmente en acuarios y bajo ciertas condiciones puede formar en el fondo un elegante y decorativo cojín; por ello se están realizando estudios biotecnológicos en cultivos in vitro para su micropropagación (Yunita et al., 2017, 2018).

2. Bacopa axillaris (Benth.) Standley, J. Wash. Acad. Sci. 15: 460. 1925. Herpestis axillaris Benth., Prodr. 10: 396. 1846. Moniera axillaris Kuntze, Revis. Gen. Pl. 2: 463. 1891. TIPO: COLOMBIA. "Deluvia Sanctae Marthae", VII1844, Purdie s.n. (Holotipo, K000533454!).

\section{Iconografias. Fig. 1A, B; Fig. 2.}

Hierbas semiacuáticas, erectas, de $20 \mathrm{~cm}$ de altura, estrigosas. Tallos carnosos, vellosos. Hojas opuestas, sésiles, estrechamente lanceoladas, 5-6 x 0,5-1 mm, ápice obtuso, base truncada, margen entero en la parte basal, ligeramente aserrado en la parte distal, con tricomas glandulares, nervadura central densamente pubescente en el envés. Flores axilares, 3-4 por axila, pedicelos de 0,5-1,2 mm long., subglabros; dos bractéolas, de 0,5-1 mm long. Cáliz con 5 sépalos, uno dorsal oval de base redondeada, dos laterales lanceolados de base redondeada y dos internos estrechamente lanceolados, ciliados en el ápice, tricomas glandulares. Corola de 3-5 mm long., blanca, internamente pubescente. Estambres 4, didínamos. Ovario ovoide, estilo entero. Cápsula estrechamente ovoide, ápice agudo, inserto en el cáliz.

Distribución geográfica y hábitat. Se distribuye en lugares húmedos de Centroamérica y Sudamérica, llegando hasta Paraguay. Previamente, citada para Paraguay por Christenhusz (2011) sin indicar un ejemplar de referencia, en este trabajo se cita para los Dptos. Cordillera y Amambay, donde habita en llanuras aluviales y en los arrozales de las ecorregiones de Chaco Húmedo y Cerrado.
Estado de conservación en Paraguay. De acuerdo con la extensión de ocurrencia (EOO) estimada en $9509 \mathrm{~km}^{2}$ debe ser considerada Vulnerable (VU), y de acuerdo al área de ocupación (AOO) estimada en $16 \mathrm{~km}^{2}$, debe ser considerada como en peligro (EN). La especie no se encuentra en todos los ambientes dentro de su extensión de ocurrencia, y las amenazas para la especie son el pastoreo de ganado y la deforestación para el cultivo de pastos y soja, que se han identificado como las principales causas de modificación del hábitat (Mereles et al., 2006, 2007; Fausto et al., 2014). Teniendo en cuenta todo lo anterior se la categoriza de forma preliminar como EN B2ab (ii, iii, iv).

Material examinado. PARAGUAY. Dpto. Amambay: Bella Vista, S22 $11^{\prime} 99^{\prime \prime}$, W56 $25^{\prime} 58^{\prime \prime}$, 11-III-2018, Madrignac \& Sosa 760, 762 (CTES, FCQ). Dpto. Cordillera: Cordillera centralis, 1900, Hassler 6412 (BM, MO); Eusebio Ayala, S22 $04^{\prime} 36^{\prime \prime}$, W55 $36^{\circ} 43^{\prime \prime}, 15-$ III-1982, Lurvey 436 (CTES, MO).

3. Bacopa congesta Chodat \& Hassl., Bull. Herb. Boissier, ser. 2, 4:289. 1904. Bacopa paraguariensis Hassl. subsp. congesta (Chodat \& Hassl.) Hassl., Pl. Hassl. Add.: 13. 1917. TIPO: PARAGUAY. Paraguarí, Tucanguá, E. Hassler 3836 (Lectotipo, G 00229867! designado por Sosa et al., Phytotaxa 336: 4. 2018; isolectotipos, BM 000098479!, G 00229864!, G 00229865!, G 00229866!, MPU 020756!, NY 00067872!, P 00753795!).

= Bacopa congesta Chodat \& Hassl. var. hirsuta Hassl. Repert. Spec. Nov. Regni Veg. 10: 348. 1912. Bacopa paraguariensis Hassl. var. hirsuta (Hassl.) Plant. Hassl. Add. 13. 1917. Bacopa hirsuta (Hassl.) Descole \& Borsini en Descole, Gen. Sp. Pl. Argent. 5: 139. 1954. TIPO: PARAGUAY. Sierra de Amambay, cerca de Estrella, T. Rojas (Herb. Hassler 10207) (Lectotipo, G 00229869! designado por Sosa et al., Phytotaxa 336: 4. 2018, isolectotipos, G 00229868!, G 00229870!, G 00229871!, K 000533463!).

Iconografías. Fig. 1C-D; Descole \& Borsini 1954: 138, tab. LXXXII; Sosa et al., 2018: 5, fig. 2.

Hierbas palustres, erectas, de $30-100 \mathrm{~cm}$ de altura, densamente híspidas con pelos escábridos. Tallos con ramificaciones superiores. Hojas opuestas, 
M. de las M. Sosa et al. - Bacopa (Plantaginaceae) de Paraguay y conservación
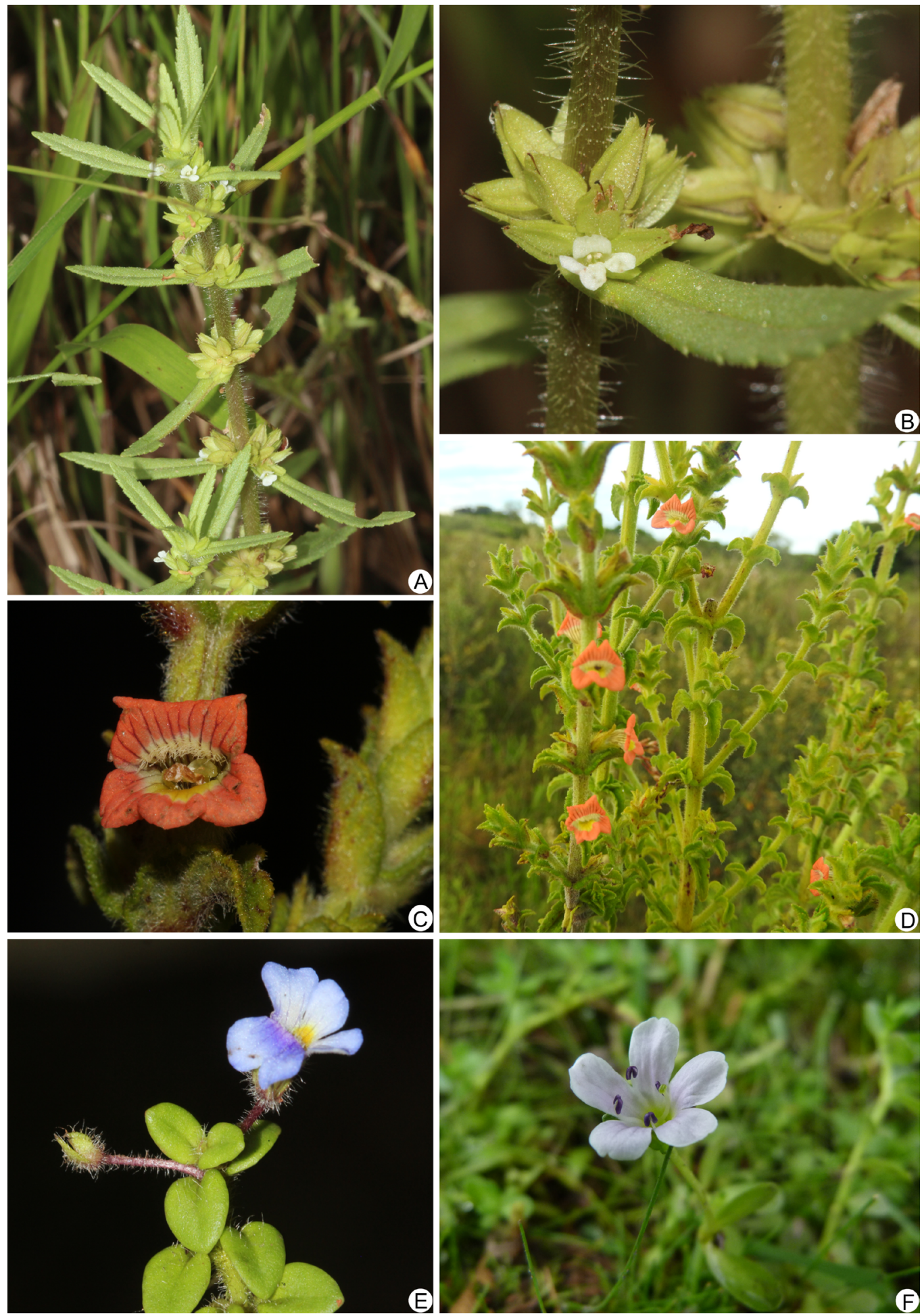

Fig. 1. A-B: Bacopa axillaris. A: aspecto de la planta. B: detalle del nudo con hojas opuestas y flores axilares blancas. C-D: Bacopa congesta. C: flor con corola anaranjada en vista frontal. D: planta. E-F: Bacopa dubia. E: detalle de las hojas, pedicelos y flor azul. Bacopa monnieri. F: detalle de la flor. 


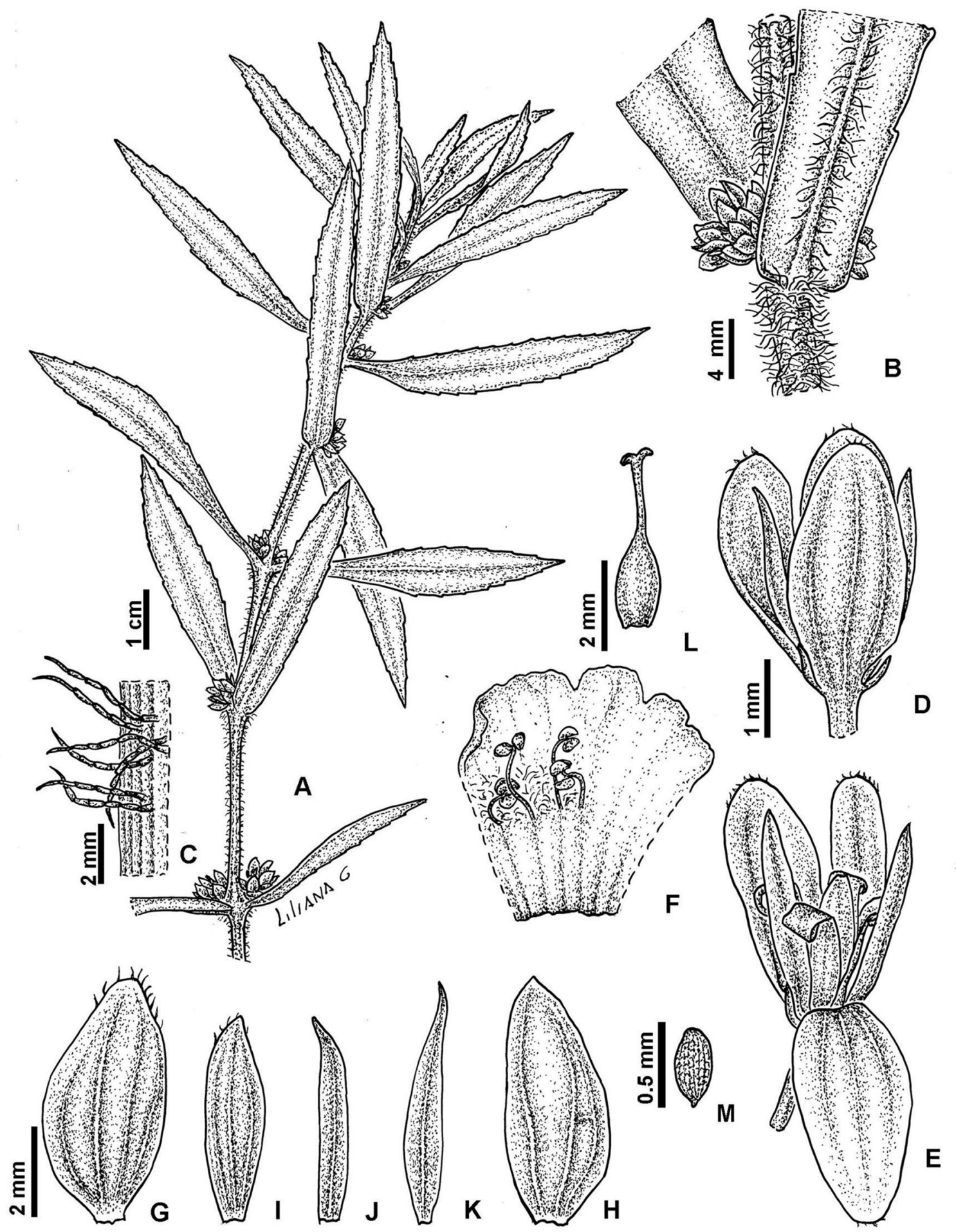

Fig. 2. Bacopa axillaris. A: aspecto de la planta. B: detalle del nudo con hojas opuestas y flores axilares. C: detalle de los tricomas en el tallo. D: cáliz. E: cáliz con los sépalos laterales abiertos. F: corola abierta mostrando el androceo. G: sépalo dorsal, vista externa. H-I: sépalos laterales, vistas externas. J-K: sépalos internos. L: gineceo. M: semilla. Ilustrado por Liliana Gómez, ejemplar Lurvey 436 (CTES). 


\section{M. de las M. Sosa et al. - Bacopa (Plantaginaceae) de Paraguay y conservación}

sésiles, angostamente ovadas o lanceoladas, 2550 x 5-10 mm, ápice agudo, base amplexicaule, margen entero o ligeramente aserrado en la parte distal, densamente híspidas. Flores dispuestas en racimos terminales, pedicelos de $3 \mathrm{~mm}$ long., híspidos; bractéolas dos, de 2-2,5 mm long. Cáliz con 5 sépalos, uno dorsal oval de base truncada, dos laterales lanceolados de base truncada y dos internos estrechamente lanceolados, tricomas densos, abundantes en las nervaduras. Corola de 8-10 mm long., anaranjada, roja o rosada, internamente pubescente. Estambres 4, didínamos. Ovario ovoide, estilo entero. Cápsula ovoide, ápice agudo, inserto en el cáliz.

Distribución geográfica y hábitat. Especie de América del Sur, crece en llanuras aluviales del sur de Brasil, Paraguay y nordeste de Argentina, hasta los $800 \mathrm{msnm}$. En Paraguay tiene una amplia distribución, especialmente en las zonas húmedas de las ecorregiones del Cerrado, Bosque Atlántico de Alto Paraná, Pastizales Mesopotámicos y el Chaco Húmedo.

Estado de conservación en Paraguay. De acuerdo a la extensión de la ocurrencia (EOO), estimada en $106,323 \mathrm{~km}^{2}$, la especie debe ser considerada como en preocupación menor (LC), y de acuerdo al área de ocupación (AOO) estimada en $108 \mathrm{~km}^{2}$, la especie debería ser evaluada como en peligro (EN). Si bien la especie se enfrenta a algunas amenazas como la deforestación para la agricultura y los incendios constantes en zonas inundables, la especie puede habitar otros ambientes, como bordes de esteros, ríos y lagunas, debido a esto se considera aquí como de menor preocupación (LC).

Material examinado. PARAGUAY. Dpto. Alto Paraná: Reserva Biológica Itaipú, "Itabó", S2521'59”, W54³4'47”, 9-IV-1991, Caballero Marmori 2019 (CTES). Dpto. Amambay: Sierras de Amambay, Cerro Corá, V-1934, S2516'00”, W5740’00”, IV-1934, Rojas 6840 (AS, LIL, MO); Ruta 3, Arroyo Negla, 290 msnm, 16XII-1983, Vanni et al. 335 (CTES); $39 \mathrm{~km}$ de Ruta 5, camino a Bella Vista, S22 $24^{\prime} 00^{\prime}$, W56 ${ }^{\circ} 17^{\prime} 00$ ', 25-X-1994, Krapovickas et al. 46025 (CTES, MO); $33 \mathrm{~km} \mathrm{~S}$ de Bella Vista por Ruta 3, S22 ${ }^{\circ} 21^{\prime}, \mathrm{W} 56^{\circ} 19^{\prime}$, 18-IV-1995, Schinini et al. 29305 (CTES); Arroyo Aceite, Parque
Nacional Cerro Corá, 6-VI-1996, Soria 7607 (FCQ, MO); ídem, S22 40'19”, W5601'31', 14VI-1996, Zardini \& Cardozo 45198, 45207 (AS, BKL, M, MO); Estancia Santa Irene, S22 $20^{\circ} 00$, W56³0’00”, 17-XI-1996, Schinini \& Barrail 31739 (CTES); Ruta 3, $35 \mathrm{~km}$ SE de Bella Vista, 16-XII-1999, Schinini et al. 1588 (CTES); Arroyo Estrella, Cerrado, S22 07'16”, W56 ${ }^{\circ} 26^{\prime} 17^{\prime \prime}$, 8-V-2000, Zardini \& Guerrero 54127 (BKL, K, M, MO). Dpto. Caazapá: Bañado de Yataymí, Ruta 6, $8 \mathrm{~km} \mathrm{SW}$ de Yuty, S26 40 '00”, W56 ${ }^{\circ} 5^{\prime} 00^{\prime}$, 22-III-1993, Schinini, Vanni \& Cáceres 27727 (CTES). Dpto. Canindeyú: Reserva Natural Mbaracayú, S2411'16", W55 16'45", 14-I-1998, Zardini \& Vera 47767 (AS, BKL, K, M, MO). Dpto. Concepción: Colonia Cristo Rey, Ruta $32 \mathrm{~km}$ de Concepción, S2320', W57 ${ }^{\circ} 10^{\prime}$, 105 msnm, 20-IV-1995, Schinini et al. 29364 (CTES). Dpto. Cordillera: regione Cordillerae centralis, prope Chololó, in valle fluminis Y-acá, S25 13'44", W57'00'04', Hassler 6736 (BM, G, MO); Yataití, S22 $04^{\prime} 36^{\prime \prime}, \mathrm{W} 55^{\circ} 36^{\prime} 43^{\prime \prime}$, III1930, Jörgensen 4527 (MO); Itacuruby, X-1971, Schinini 3907 (CTES); Cerro Zebaty, 1-III-1972, Schinini 4423 (CTES); Cordillera de Altos, Cerro de Tobatí, S2513'44”, W5700'40”, 8-III-1984, Schinini 23999 (BAB, CTES); Altos, camino a Soma Grande, S25 $17^{\prime} 00^{\prime \prime}$, W5 $7^{\circ} 15^{\prime} 00^{\prime \prime}, 20$-III1989, Degen 1420 (MO); Tobatí, "Ybytú Silla", S2512'00”, W5707'00”, 297 m, 3-III-1991, Zardini \& Velázquez 26742 (FCQ, MO). Dpto. Guairá: Villarica, Ciudad Universitaria, 2-IV1985, Bordas 3842 (CTES). Dpto. Itapuá: San Cosme, Arroyo Abingy, 21-II-1956, Pedersen 4374 (CTES); Isla Yaciretá, 23-IV-1993, Quintana et al. 286 (CTES). Dpto. Paraguarí, Carapeguá, Calistro, S2546'00", W5708'00", II-1919, Rojas 3390 (AS, MO); Valenzuela, S25 $35^{\prime}$ W56 ${ }^{\circ} 52^{\prime}$, III1942, Rojas 9510 (MO); Parque Nacional Ybycu'í, S26 03'00', W56 50'00”, 27-I-1989, Zardini 10244 (MO, PY). Dpto. San Pedro: Lima, Estancia Carumbé, 24-II-1975, Pedersen 11161 (CTES).

4. Bacopa dubia Chodat \& Hassl., Bull. Herb. Boissier, ser. 2, 4: 289. 1904. TIPO: PARAGUAY. "In palude Tapangua", X-1898-1899, E. Hassler 3309 (Lectotipo, G 00307148! designado por Sosa et al., Phytotaxa 336: 6. 2018, isolectotipos BM 000953363!, G 00307156!, G 00307158!, MPU 020755!, S-04-3405!). 
Iconografias. Fig. $1 \mathrm{E}$; Descole \& Borsini 1954: 134, tab. LXXIX; Sosa et al., 2018: 7, fig. 3.

Hierbas semiacuáticas, rastreras, de 7-20 cm, estrigosas. Tallos ascendentes, estrigosos. Hojas opuestas, sésiles, ovadas a suborbiculares, 6-10 x 4-6 mm, ápice y base redondeados, margen entero, estrigosas. Flores axilares, solitarias, pedicelos hasta $50 \mathrm{~mm}$ long., estrigosos; sin bractéolas. Cáliz con 5 sépalos, uno dorsal oval de base cordada a subcordada, dos laterales ovales de base cordada a subcordada y dos internos linear-lanceolados, suavemente pubérulo, tricomas en los márgenes y nervaduras. Corola de $8-10 \mathrm{~mm}$ long., blanca o celeste, glabra. Estambres 4, didínamos. Ovario ovoide, estilo bifurcado. Cápsula ovoide, ápice agudo.

Distribución geográfica y hábitat. Especie de América del Sur, crece en Paraguay y el nordeste de Argentina (Corrientes y Misiones), hasta los $500 \mathrm{msnm}$. En Paraguay, habita en cuerpos de agua o zonas inundables de varios departamentos, abarcando las ecorregiones del Chaco Húmedo, Pastizales Mesopotámicos y Bosque Atlántico del Alto Paraná.

Estado de conservación en Paraguay. De acuerdo a la extensión de ocurrencia (EOO) estimada en $82,435 \mathrm{~km}^{2}$ la especie debería ser evaluada como en menor preocupación (LC), y de acuerdo al área de ocupación (AOO) estimada en 68 $\mathrm{km}^{2}$, la especie debe ser evaluada como en peligro de extinción (EN). Las amenazas potenciales para esta especie son el avance de la agricultura y la colmatación y contaminación de los cuerpos de agua, lo cual produce una disminución en la calidad del hábitat (Fleytas, 2007; Mereles et al., 1992, 2006, 2007, 2015). Sin embargo, estas amenazas no representan aún un grado mayor para la especie en la actualidad. Debido a lo anterior la especie se considera aquí como de preocupación menor, LC.

Material examinado. PARAGUAY. Dpto. Alto Paraná: Ruta Mariscal Estigarribia, km 218, 28-IX1967, Pedersen 8435 (CTES); Reserva Biológica Tatí Yupí, 20-IV-1989, Caballero Marmori 1634 (CTES). Dpto. Central: Ypacaraí, 1885-1895, Hassler $870(\mathrm{G})$; Tucangua, S20 $28^{\prime}$, W59 ${ }^{\circ} 63^{\prime}$, Hassler 1195 (C, K); Tobaty, Hassler 6161 (G);
San Lorenzo, 16-X-1973, Schinini 7515 (CTES); Areguá, orillas del Riacho Negro, 5-I-1979, Mereles 177 (CTES); Estero Areguá, IX-1983, Mereles 152 (CTES); Estero del Ypoá, 10 km SW de Nueva Italia, S25 20 '00”, W57 $28^{\prime} 00^{\prime \prime}, 27$ I-1990, Zardini \& Velázquez 18420, 18494 (AS, MO); Estero del Ypoá, 13 km SW de Nueva Italia, S2520'00", W57²8'00”, 27-I-1990, Zardini \& Velázquez 18543 (AS, MO); $15 \mathrm{Km} \mathrm{SW}$ de Nueva Italia, S27²4'00", W57³2'00", 10-II-1990, Zardini \& Velázquez 18815 (AS, MO); ídem, 200 m, S25 20'00", W57²8'00", 10-II-1990, Zardini \& Velázquez 18974 (AS, MO); ídem, S27²0’00", W57²8'00”, 10-II-1990, Zardini \& Velázquez 18830 (AS, MO); ídem, 7-XII-1990, Zardini \& Velázquez 24897 (AS, MO); ídem, S2520'00", W57²8'00", 7-XII-1990, Zardini \& Salina 24987 (AS, MO). Dpto. Cordillera: Piribebuy, 1885-1895, Hassler 1927 (G); San Bernardino, Lago Ypacaraí, 3-XI-1950, Rojas 14315 (LIL); San Bernardino, VII-1988, Mereles 1259 (FCQ). Dpto. Guairá: Villa Rica, 2-III-1929, Jörgensen 3724 (MO); Colonia Independencia, 29-III-1972, Pedersen 10099 (CTES). Dpto. Itapuá: Isla Yaciretá, 23-IV1993, Quintana et al. 284 (CTES). Dpto. Misiones: Reserva del Yabebyry, Estancia Santa Ana, 21II-1993, Florentín Peña et al. 954 (CTES). Dpto. Neembucú: Paso de la Patria, Laguna del puerto, S2714'57.9”, W58 32'32.7’, 8-II-2017, Mereles \& Esquivel 10419 (FCQ). Dpto. Paraguarí: Estero del Ypoá, $20 \mathrm{~km}$ W de Carapeguá, 25-XI-1950, Sparre \& Vervoorst 569 (LIL); Arroyo Yuquyty, 7 km E de Nueva Italia, S25 36', W57 ${ }^{\circ} 5^{\prime}, 14$ XII-1989, Zardini \& Velázquez 17016 (AS, MO); Estero del Ypoá, 19 km de Carapeguá, S2517’00”, W57²5’00", 7-I-1990, Zardini \& Velázquez 17516 (AS, MO); ídem, S25 47’00", W57²5'00”, 7-I1990, Zardini \& Velázquez 17604 (AS); ídem, 7-I-1990, Zardini \& Velázquez 17653, 17778 (AS, MO); ídem, 13-I-1990, Zardini \& Velázquez 17934, 17997 (AS, MO); ídem, S2517' W57²5', 27-I-1990, Zardini \& Velázquez 18374 (AS, MO); Estero del Ypoá, $10 \mathrm{~km}$ E de Nueva Italia, Arroyo Cañabe, S2537’00”, W57²4'00”, 8-XII-1990, Zardini \& Velázquez 25198 (AS, MO).

5. Bacopa gratioloides (Cham.) Edwall, Bolm. Commiss. Geogr., Estado São Paulo 13: 175. 1897. Caconapea gratioloides Cham., Linnaea 8: 29. 1833. Herpestis gratioloides (Cham.) Benth., 


\section{M. de las M. Sosa et al. - Bacopa (Plantaginaceae) de Paraguay y conservación}

Companion Bot. Mag. 2: 57. 1836. Herpestis caconapea (Cham.) Steud., Nomencl. Bot., ed. I., 402: 753. 1840. SINTIPOS: BRASIL. "Brasilia, Sellow”, Sello s.n. (Probable en B, no localizado); "Bahía", Lhotzki s.n. (Probable en B, no localizado).

Hierbas palustres, erectas, de $25-60 \mathrm{~cm}$, glabras. Tallo raro ramificado y ascendente, glabro, con puntos glandulares. Hojas opuestas, sésiles, linearlanceoladas o lineales, arqueadas, 3-8 × 0,15-2 $\mathrm{mm}$, ápice agudo a acuminado, base envainadora, margen entero, con puntos glandulares. Flores axilares, 2-5 por axila, pedicelos 1-2 mm long., subglabros; dos bractéolas, 2-2,5 mm long. Cáliz con 5 sépalos, sépalo dorsal, laterales e internos angostamente lanceolados, de base aguda y los dos sépalos internos lanceolados, subglabros. Corola de 6-8 $\mathrm{mm}$ long., azul o violácea, internamente pubescente. Estambres 4, didínamos. Ovario ovoide, estilo entero. Cápsula ovoide, ápice agudo, inserto en el cáliz.

\section{Iconografia. Fig. 3.}

Distribución geográfica y hábitat. Especie de América del Sur, hasta los $550 \mathrm{msnm}$. Habita en pastizales inundables de Brasil y Paraguay (Amambay y Concepción), en bordes de arroyos de las ecorregiones del Chaco Húmedo y Cerrado.

Estado de conservación en Paraguay. Basado en la extensión de ocurrencia (EOO), estimada en $26,384 \mathrm{~km}^{2}$, debería ser considerada como casi amenazada (NT) y de acuerdo a su AOO estimado en $32 \mathrm{~km}^{2}$, la especie debe ser considerada como en peligro. La principal amenaza a la que se enfrenta la especie es el fuerte avance del cultivo de soja en los pastizales naturales en los últimos años, que aumenta año tras año, en menor medida, la construcción de caminos ha producido una disminución en la calidad del hábitat (Fausto et al., 2014; Mereles et al., 2006, 2015). Teniendo en cuenta todo lo anterior se la categoriza de forma preliminar como EN B2 ab (ii, iii).

Material examinado. PARAGUAY. Dpto. Amambay: regione cursus superioris fluminis Apa, 1901-1902, Hassler 7982 (MO); Río Apa y Río Aquidaban, 1908-1909, Fiebrig 4439 (BM, $\mathrm{K}$ ); Bella Vista, Estancia del Sr. Ocaris, $10 \mathrm{~km}$ del
Colonia Sargento Duré, $26 \mathrm{~km} \mathrm{~S}$ de Bella Vista, camino a Ruta 5, S22 ${ }^{\circ} 17^{\prime} 19,9^{\prime \prime}, \mathrm{W} 56^{\circ} 22^{\prime} 17,7^{\prime \prime}$, 232 m, 15-III-1983, Cowan et al. 4169 (CTES, TEX); $26 \mathrm{~km} \mathrm{~S}$ de Bella Vista, camino a Ruta 5, S22 ${ }^{\circ}$ 17'19,9”, W56 22'17,7”, 232 m, 8-III-2009, Keller et al. 6747 (CTES). Dpto. Caaguazú: Estero del Ypoá, $15 \mathrm{~km}$ SE de Nueva Italia, Zardini \& Velazquez 18700 (AS). Dpto. Concepción: Puerto Riso, 16-I-1955, Schulz 8836 (CTES); Estancia Centurión, Potrero Toro, Laguna Pe, $200 \mathrm{~m}$, S22 ${ }^{\circ} 5^{\prime}$ '57', W57³2'56”, 18-X-1994, Stevens et al. 26339 (FCQ, MO).

6. Bacopa monnieri (L.) Wettst., Nat. Pflanzenfam. 67: 77. 1891. Lysimachia monnieri L., Cent. Pl. II: 9. 1756. Gratiola monnieri L., Amoen. Acad. Linnaeus ed. 4: 306. 1759. Capraria monnieria Roxb., Hort. Bengal.: 47. 1814. Herpestis monnieria (L.) Kunth, Nov. Gen. Sp. 2: 366. 1818. Bramia monniera (L.) Drake, Fl. Polynésie. Franç.: 142. 1893. Bramia monnieri (L.) Pennell, Proc. Acad. Nat. Sci. Philadelphia 71: 243. 1920. TIPO: JAMAICA. P. Browne, Civ. Nat. Hist. Jamaica 269, t. 28, f. 3. 1756 (Neotipo designado por Cramer, Revis. Handb. Fl. Ceylon. 3: 421. 1981.).

= Bramia indica Lam., Encycl. 1: 459. 1785. TIPO: P-LA! (Lectotipo P 00357973! designado por Sosa et al., Phytotaxa 336: 8. 2018).

Iconografias. Fig. 1F; Descole \& Borsini 1954: 136, tab. LXXIII; Sosa et al., 2018: 8, fig. 4.

Hierbas terrestres, rastreras, de 10-20 cm, glabras. Tallos rastreros, algunos ascendentes, glabros. Hojas opuestas, sésiles, obovadas o espatuladas, 5-15 x 2-5 mm, ápice obtuso, base aguda, margen entero, glabras. Flores axilares, solitarias, pedicelos hasta 20 mm long.; dos bractéolas, 0,5-1 mm long. Cáliz con 5 sépalos, uno dorsal oval de base subcordada, dos laterales ovales de base subcordada y dos internos linear-lanceolados, glabro. Corola de 7-8 mm long., blanca o celeste, glabra, Estambres 4, didínamos. Ovario ovoide, estilo entero. Cápsula ovoide, ápice agudo.

Distribución geográfica y hábitat. Es una especie cosmopolita, presente en todo el mundo. En Paraguay es frecuente encontrarla formando parte de pastizales con suelos húmedos, arenosos o pantanosos en las ecorregiones del Chaco Húmedo y Chaco Seco. 


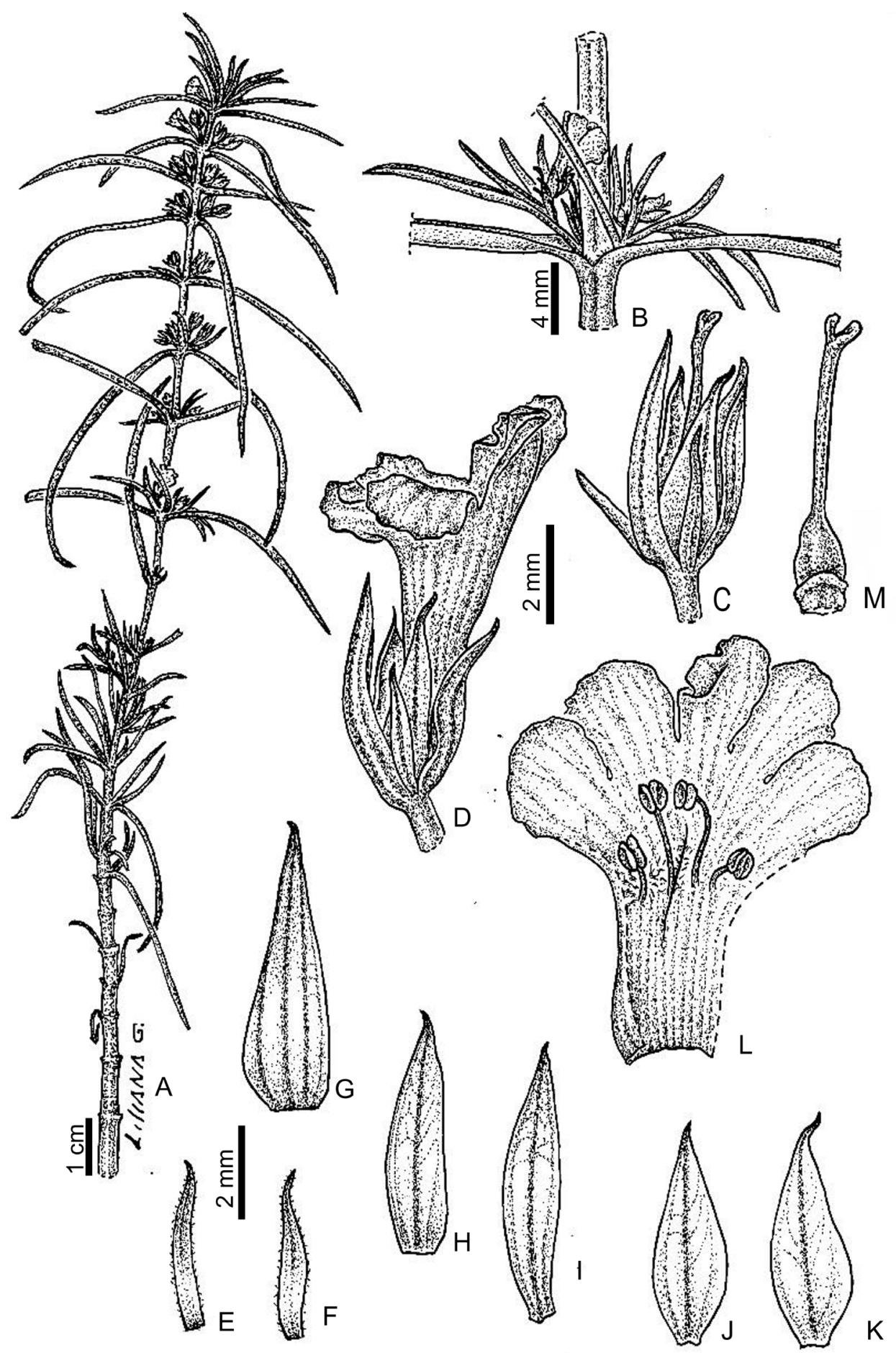

Fig. 3. Bacopa gratioloides. A: aspecto de la planta. B: detalle del nudo con hojas opuestas y flores axilares. C: cáliz. D: flor. E- F: bractéolas. G: sépalo dorsal, vista externa. H-I: sépalos laterales, vistas externas. K: sépalos internos. L: corola abierta mostrando el androceo. M: gineceo. Ilustrado por Liliana Gómez, ejemplar Queiroz et al. 7712 (CTES). 


\section{M. de las M. Sosa et al. - Bacopa (Plantaginaceae) de Paraguay y conservación}

Nombres vulgares. "Berro", "bramia".

Estado de conservación en Paraguay. Basado en un EOO de 95,636 km² esta especie debería ser considerada como en preocupación menor (LC) y un AOO de $44 \mathrm{~km}^{2}$ debería ser considerada en peligro (EN). Las principales amenazas a la que se enfrenta, que llevan a una reducción de su hábitat son la deforestación para la agricultura y la ganadería, sumado a los incendios constantes en las zonas inundables del Chaco Húmedo y Seco con la consiguiente reducción de la cobertura vegetal (Fleytas, 2007; Fausto et al., 2014; Mereles et al., 2015). Teniendo en cuenta todo lo anterior se la categoriza de forma preliminar como EN B2ab (ii, iii, iv).

Material examinado. PARAGUAY. Dpto. Boquerón: Tinfunké, orillas del Río Pilcomayo, 30-X-1985, Mereles 520 (CTES). Dpto. Central: Río Pilcomayo,1888-1890, Morong 90 (MO); ídem, S22 04'36”, W55³6'43”, 1888-1890, Morong 1029 (MO); ídem, 1-1917, Rojas 2506 (LIL), Asunción, Santísima Trinidad, S2516'00", W5740'00”, 6-III-1947, Pavetti Morín 3154 (AS, MO); ídem, 3-XII-1950, Sparre \& Vervorst 7648 (LIL); orillas del Río Paraguay, V-1972, Insfran 1076 (CTES); Parque Caballero, 3-I-1974, Schinini 8027 (CTES); Patiño, trayecto a Ypacaraí, Arroyo Santo Domingo, 13-XI1978, Mereles 28 (CTES); Ñemby a $100 \mathrm{~m}$ de la Ruta, 29-I-1982, Pérez de Molas \& González 45 (MO); cercanías de Limpio, 13-II-1991, Soria 4270 (MO). Dpto. Cordillera: orillas de Río Manduvirá, 26-VI-1986, Mereles 766 (CTES). Dpto. Nembucú: Humaitá, 12-XII-1950, Schulz 7744 (CTES). Dpto. Presidente Hayes: Estancia

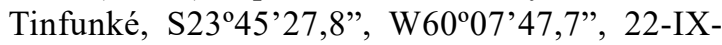
1994, Mereles \& Degen 5802 (CTES, FCQ).

7. Bacopa monnierioides (Cham.) B.L.Rob., Proc. Amer. Acad. Arts 44: 614. 1909. Ranaria monnierioides Cham., Linnaea 8: 31: 1833. Herpestis ranaria (Cham.) Benth., Companion Bot. Mag. 2: 57. 1836, nom. ileg. superfl. Monniera monnierioides (Cham.) Kuntze, Revis. gen. pl. 2: 463. 1891. Monniera ranaria (Cham.) Fritsch., Bih. Soensk. Vet. Akad. Handl. 24: 510. 1898. Bacopa ranaria (Cham.) Chodat \& Hassl., Bull. Herb. Boissier, ser. 2, 4: 288. 1904, comb. ileg. TIPO: BRASIL. "Brasilia, Sellow", Sello s.n. (Lectotipo, K 000533423! designado por Souza \& Giulietti, Pesquisas Bot. 60: 27. 2009, isolectotipo HAL 0115853 !).

= Bacopa ranaria var. guaranitica Chodat \& Hassler, Bull. Herb. Boissier, ser. 2, 4: 288. 1904. TIPO: PARAGUAY. "In palude pr. Tobaty", IX1900, E. Hassler 6412 (Lectotipo, designado por Sosa et al., Phytotaxa 236: 10. 2018, G00229874!, isolectotipos, BM 000098488!, G 00229872!, G 00229873!, K 000533422!, MPU 020754!, NY 00067876!).

= Caconapea appressa Pennell, Proc. Acad. Nat. Sci. Philadelphia 72: 152. 1920. TIPO: COLOMBIA. Meta, east of Villavicencio, 26-VIII-1917, F. W. Pennell 1460 (Holotipo, NY00067933!, isotipos, CAS0001555!, GH 00078025 !, F 0072320F!, K 000533455!, PH 00010106!, US 00122508!).

= Bacopa parviflora Standley ex Williams. Fieldiana Bot. 34: 118. 1972. TIPO: PANAMA. Prov. Panamá, Tecumen River, vicinity of Juan Díaz, 9-XI-1017, E. P. Killip 3420 (Holotipo, F 0093089!).

Iconografías. Descole \& Borsini 1954: 143, tab. LXXB; Sosa et al., 2018: 10, fig. 5.

Hierbas semiacuáticas, erectas, de $5-30 \mathrm{~cm}$, subglabras. Tallos ascendentes, subglabros. Hojas opuestas, sésiles, ovado-elípticas, 10-30 x 8-12 mm, ápice agudo, base amplexicaule, margen entero, pubérulas. Flores axilares, 2-3 por axila pedicelo breve, 1-2 $\mathrm{mm}$ long., ligeramente pubérulo; dos bractéolas, 1-1,5 $\mathrm{mm}$ long. Cáliz con 5 sépalos, uno dorsal oval de base subcordada a truncada, dos laterales ovales de base subcordada y dos internos linearlanceolados. Corola de $2 \mathrm{~mm}$ long., blanca o lila, glabra. Estambres 4, de igual longitud. Ovario ovoide, estilo entero. Cápsula ovoide, ápice agudo.

Distribución geográfica y hábitat. Esta especie crece en pantanos, lugares fangosos con agua estancada y en sabanas húmedas. Se la encuentra desde México hasta el nordeste de Argentina, hasta los $1000 \mathrm{msnm}$. En Paraguay habita en llanuras aluviales de las ecorregiones del Chaco Húmedo y Bosque Atlántico del Alto Paraná. 
Estado de conservación en Paraguay. De acuerdo con la extensión de ocurrencia (EOO) estimada en $21,080 \mathrm{~km}^{2}$ la especie debería ser evaluada como vulnerable (VU), y de acuerdo al área de ocupación (AOO) estimada en $16 \mathrm{~km}^{2}$, la especie debe ser evaluada como en peligro (EN). Solo se registraron cuatro poblaciones, todas restringidas a la parte Oriental del Paraguay, en los departamentos de Cordillera, Guairá y San Pedro, en donde se ha observado un continuo declive en la calidad del hábitat adecuado para esta especie. Esto se debe principalmente a los avances de la agricultura y ganadería en el Bosque Atlántico del Alto Paraná (Mereles et al., 1992, 2006, 2007; Fleytas, 2007). Teniendo en cuenta todo lo anterior se la categoriza de forma preliminar como EN B2ab (ii,iii).

Material examinado. PARAGUAY. Dpto. Cordillera: Cordillerae Centralis, in regione collium, Cerros de Tobaty, Hassler 6412 (BM, G, LIL, NY, P); ídem, S22 04'36”, W55 $36^{\circ} 43^{\prime \prime}$, 2-X-1928, Jörgensen 4366 (MO). Dpto. Guairá: General Eugenio A. Garay, 6-III-2018, Madrignac \& Sosa 651 (FCQ, CTES). Dpto. San Pedro: Lima, Estancia Carumbé, Pedersen 11155 (CTES).

8. Bacopa paraguariensis (Moore) Hassl. Pl. Hassl. Add. 13: 1917. Herpestis paraguariensis S. Moore, Trans. Linn. Soc. London, Bot. ser. 2, 4: 407. 1895. TIPO: PARAGUAY. Caaguazú, 1876, B. Balansa 2142 (Holotipo, K 000533457 !).

Iconografias. Descole \& Borsini 1954: 140, tab. LXXXIV; Sosa et al., 2018: 12, fig 6.

Hierbas palustres, erectas, de $35-80 \mathrm{~cm}$, pubérulas. Tallos ascendentes, algunos postrados, pubérulos. Hojas opuestas, sésiles, oblongas a angostamente ovadas, $25-45 \times 5-10 \mathrm{~mm}$, ápice agudo, base auriculada, margen entero o ligeramente serrado en la parte distal, pubérulas. Flores axilares, solitarias o 2 por axila, pedicelos 4-15 mm long, pubérulos; dos bractéolas, $1 \mathrm{~mm}$ long. Cáliz con 5 sépalos, uno dorsal oval de base truncada, dos laterales lanceolados de base truncada y dos internos estrechamente lanceolados, tricomas cortos, abundantes en las nervaduras. Corola de 7-8 mm long., lila, pubescente. Estambres 4, didínamos. Ovario ovoide, estilo entero. Cápsula globosa, ápice redondeado.
Distribución geográfica y hábitat. Esta especie crece en América del Sur, en zonas inundables del Paraguay y norte de Argentina, hasta los 500 msnm. Habita en pastizales húmedos, depresiones inundables, cercano a cursos de agua de la ecorregión Bosques Atlánticos del Alto Paraná.

Estado de conservación en Paraguay. De acuerdo con la EOO estimada en $1,623 \mathrm{~km}^{2}$ y el AOO estimada en $12 \mathrm{~km}^{2}$, la especie debería ser considerada en peligro de extinción (EN). Solo se registraron dos poblaciones restringidas a los departamentos Caaguazú y Guairá, en donde se ha observado un continuo declive en la calidad del hábitat adecuado para esta especie. Esto se debe principalmente a los avances de la agricultura y ganadería, y la invasión de especies exóticas en el Bosque Atlántico del Alto Paraná (Mereles et al., 1992, 2006, 2007; Fleytas, 2007). Teniendo en cuenta todo lo anterior se la categoriza de forma preliminar como EN B1b (ii, iii, iv) + 2b (ii, iii).

Material examinado. PARAGUAY. Dpto. Caaguazú: 1876, B. Balansa 2142 (K). Dpto. Guairá: Azucarera de Tebicuary, Rí Tebicuary, 12-I-1973, Schinini 5894 (CTES); ídem, S22 ${ }^{\circ} 04^{\prime}$ W55 36', Pedro Jörgensen 4524 (MO).

9. Bacopa repens (Sw.) Wettst., Natur. Pflanzenfam. 67(4, 3b): 76. 1895. Gratiola repens Sw., Prodr. 14: 1788. Herpestis repens (Sw.) Schltdl. \& Cham., Linnaea 5: 107. 1830. Macuillamia repens (Sw.) Pennell, Proc. Acad. Nat. Sci. Philadelphia 75: 9. 1923. TIPO: JAMAICA, VI-1786, O. P. Swartz s.n. (Lectotipo, S 04-341! designado por Sosa et al., Phytotaxa 336: 11. 2018, isolectotipos, BM 000953377!, LINN-HS No. 48-3!, LD 1741638!, S-R-2471!, S-R-2470!).

= Macuillamia limosa Pennell, Proc. Acad. Nat. Sci. Philadelphia 72: 158. 1920. Bacopa limosa (Pennell) Standley, J. Wash. Acad. Sci. 15: 460. 1925. TIPO: COLOMBIA. Cundinamarca, Melgar, 400-500 m, F. W. Pennell 2927 (Holotipo, NY 00090653, isotipos CAS 0003270!, PH 00016463!, US 00122518!).

= Bacopa cladostyla Eskuche, Folia Bot. Geobot. Corrent. 3: 11. 1989. TIPO: PARAGUAY. San Bernardino, campo estero Ciervo-cuá, II-1915, T. Rojas 1043 (Holotipo, LIL 222.457!, isotipo, LIL 70170 ex GH!). 


\section{M. de las M. Sosa et al. - Bacopa (Plantaginaceae) de Paraguay y conservación}

Iconografia. Sosa et al., 2018: 13, fig. 7.

Hierbas acuáticas, rastreras; de $5-10 \mathrm{~cm}$, estrigosas. Tallos ascendentes, estrigosos. Hojas opuestas, sésiles, ovado-elípticas, 6-8 x 5-7 mm, ápice y base redondeados, margen entero, base y nervaduras densamente pubescentes. Flores axilares, solitarias, pedicelos hasta $5 \mathrm{~mm}$ long., vellosos; sin bractéolas. Cáliz con 5 sépalos, uno dorsal oval de base cordada a subcordada, dos laterales ovales de base cordada a subcordada y dos internos linearlanceolados, con tricomas en las nervaduras. Corola de 2-3 mm long., blanca, externamente pubérula. Estambres 2, de igual longitud. Ovario ovoide, estilo bifurcado. Cápsula ovoide, ápice agudo.

Distribución geográfica y hábitat. Crece desde los Estados Unidos hasta la Argentina, hasta los 500 msnm. También se ha citado para China (Deyuan et al., 1998). En Paraguay habita en áreas inundables, lagos, lagunas y esteros de la ecorregión del Chaco Húmedo.

Estado de conservación en Paraguay. De acuerdo a la extensión de ocurrencia (EOO) estimada en $25,888 \mathrm{~km}^{2}$, la especie debería ser evaluada como casi amenazada (NT), y de acuerdo a su área de ocupación (AOO), estimada en $12 \mathrm{~km}^{2}$, esta especie debería ser avaluada como en peligro (EN). Solo se registraron tres poblaciones confinadas a dos departamentos (Central y Presidente Hayes), que presentan áreas severamente fragmentadas por la deforestación para el cultivo, sumado al uso indiscriminado de pesticidas, los cuales, son transportados por las aguas de lluvia y efluentes hacia los lagos y lagunas, provocando la eutrofización de los mismos (Mereles et al., 1992, 2007). Teniendo en cuenta todo lo anterior se la categoriza de forma preliminar como EN B2b (ii, iii, iv).

Material examinado. PARAGUAY. Dpto. Central: San Bernardino, campo estero CiervoCuá, II-1915, Rojas 1043 (LIL). Dpto. Itapuá: Encarnación, 1915, Hassler 1384 (G). Dpto. Presidente Hayes: Pozo Colorado, S23 $3^{\circ} 6^{\prime} 00^{\prime \prime}$, W59¹7'00", 15-IV-1994, Mereles 5530 (CTES, FCQ, MO).

10. Bacopa rotundifolia (Michx.) Wettst., Nat. Pflanzenfam. 67 (4, 3b): 76. 1891. Monniera rotundifolia Michx., Fl. Bor-Amer. 2: 22. 1803. Herpestis rotundifolia (Michx.) Pursh., Fl. Amer. Sep. 2: 418. 1813. Macuillamia rotundifolia (Michx.) Raf., Autik. bot.: 44. 1840. Ranapalus rotundifolius (Michx.) Pennell, Proc. Acad. Nat. Sci. Philadelphia 71: 242. 1920. TIPO: ESTADOS UNIDOS. Illinois, État de l'Illinois, V-1849, A. Trécul 742 (Neotipo, P 03535493!, designado por Sosa et al., Phytotaxa 336: 14. 2018, isoneotipos $\mathrm{P}$ 03535482!, P 03535499!).

= Herpestis tweedie Benth., Prodr. 10: 397. 1846. Monniera tweedii (Benth.) Kuntze, Revis. Gen. Pl. 2: 463. 1891. Bacopa tweedie (Benth.) Parodi, Revista Fac. Agron. Veterin. 7: 240. 1930. TIPO: ARGENTINA. Córdoba, J. Tweedie s.n. (Lectotipo, K 000373794!, designado por Sosa et al., Phytotaxa 336: 14. 2018, isolectotipo, K 000533445).

= Herpestis eiseni (Kellogg) Geene, Man. Bot. San Franc. Bay: 278. 1894. Macuillamia eisenii (Kellogg) Pennell, Acad. Nat. Sci. Philadelphia Monogr. 1: 57. 1935. Bacopa eisenii (Kellogg) Pennell, Proc. Acad. Nat. Sci. Philadelphia 98: 96. 1946.

= Macuillamia limosa Pennell, Proc. Acad. Nat. Sci. Philadelphia 72: 158. 1920. Bacopa limosa (Pennell) Standl., J. Wash. Acad. Sci. 15: 460. 1925. TIPO: COLOMBIA. Cundinamarca, Melgar, XII-1917, F. W. Pennell 2927 (Holotipo, NY 00090653!, isotipos, CAS 0003270!, PH 00016463!, US 00122518!).

= Bacopa simulans Fernald, Rhodora 44: 438 . 1942. TIPO: ESTADOS UNIDOS. Virginia, Charles City County, sandy-muddy fresh tidal shore of Chickahominy River, Graves Landing, north of Holderoft, 10-IX-1941, M. L. Fernald \& B. H. Long 13749 (Lectotipo, GH 00077923!, designado por Sosa et al., Phytotaxa 336: 14. 2018, isolectotipos, BM 001025113!, BRIT 23358!, F 0072297F!, GH 00077924!, K 000979484!, MICH 1109980!, NY00067865!, US 00036890!, WIS v0256278!).

= Bacopa nobsiana Mason, Madroño 11: 206. 1952. TIPO: ESTADOS UNIDOS. California, Sutter bypass, just south of Marysville, Sutter County, 29-VII-1949, M. Nobs \& S. G. Smith 1097 (Holotipo, UC 927650!, isotipos, CAS 0027916!, K 000979488!, NY 00067864!).

Iconografias. Descole \& Borsini 1954: 135, tab. LXXX; Sosa et al., 2018: 15, fig. 8. 
Hierbas semiacuáticas, rastreras, de $20-30 \mathrm{~cm}$, subglabras. Tallos ascendentes, subglabros. Hojas opuestas, sésiles, orbiculares u suborbiculares, 10-14 x 10-13 mm, ápice obtuso, base redondeada, margen entero, glabras. Flores axilares, solitarias, pedicelos de 5-10 mm long, subglabros; sin bractéolas. Cáliz con 5 sépalos, glabro, uno dorsal oval de base subcordada a truncada, dos laterales ovales de base truncada y dos internos lanceolados. Corola de 4,5$5 \mathrm{~mm}$ long., blanca, glabra. Estambres 4, de igual longitud. Ovario ovoide, estilo bifurcado. Cápsula ovoide, ápice redondeado.

Distribución geográfica y hábitat. Esta especie tiene una amplia distribución geográfica, desde los Estados Unidos hasta el norte de Argentina, hasta los $500 \mathrm{msnm}$. En Paraguay crece en áreas inundables, lagunas y esteros de la ecorregión del Chaco Húmedo.

Estado de conservación en Paraguay. De acuerdo a la extensión de ocurrencia (EOO) estimada en $32,566 \mathrm{~km}^{2}$ la especie debería ser evaluada como casi amenazadas (NT) y de acuerdo a su área de ocupación (AOO) de $12 \mathrm{~km}^{2}$, esta especie debería ser considerada en peligro (EN). Las poblaciones se encuentran muy fragmentadas y las principales amenazas para esta especie son la actividad ganadera en la región, así como los incendios periódicos provocados, sumado a la eutrofización de los lagos y lagunas (Mereles et al., 1992, 2007). Teniendo en cuenta todo lo anterior se la categoriza de forma preliminar como EN B2ab (ii, iii).

Material examinado. PARAGUAY. Dpto. Central: Asunción, XI-1946, Rojas 1070 (LIL). Dpto. Concepción: Estancia Tres Hermanos, Potrero Aquidavan, Fiebrig 4495 (G, K); ídem, 10VII-1991, Basualdo 3291 (FCQ). Dpto. Paraguarí: Pirayú, Estancia Romero Pereira, VIII-1990, Mereles 3934 (FCQ 22538). Dpto. Presidente Hayes: Santa Elisa, 1903, Hassler 2828 (MO); localidad no indicada, XI-1930, Jörgensen 4234 (MO); Ruta 12, $5 \mathrm{~km}$ del Chaco, 20-VI-1975, Krapovickas \& Schinini 28571 (CTES); Pozo Colorado, 15-IV-1994, Mereles \& Degen 5530 (CTES; FCQ; MO); Tte. Esteban Martínez, 28-XI2000, Mereles et al. 8301 (FCQ); Km 65, Estancia Santa María del Doce, 1-XII-2003, Mereles 9089 (CTES, FCQ).
11. Bacopa salzmannii (Benth.) Wettst. ex Edwall, Bolm. Commiss. Geogr. Estado São Paulo 13: 175. 1897. Herpestis salzmannii Benth., Companion Bot. Mag. 2: 58. 1836. TIPO: BRASIL. Bahía, P. Salzmann s.n. (Lectotipo, K 000533400!, designado por Sosa et al., Phytotaxa 336: 16. 2018, isolectotipos, HAL 0115854!, K 000533400!, MO 503753!).

= Monocardia violacea Pennell, Proc. Acad. Nat. Sci. Philadelphia 72: 156. 1920. Bacopa violacea (Pennell) Stand., J. Wash. Acad. Sci. 15: 460. 1925. TIPO: COLOMBIA. Near Villavicenco, $50 \mathrm{~m}$, 28-VIII-1917, F. W. Pennell 1480 (Holotipo, NY 00090826!, isotipos, GH 00078967!, K 000533448!, PH 00018342!, US 00122507!).

= Monocardia humilis Pennell, Proc. Acad. Nat. Sci. Philadelphia 72: 157. 1920. Bacopa humilis (Pennell) Stand., J. Wash. Acad. Sci. 15: 460. 1925. TIPO: COLOMBIA. Huila, east of Neiva, 8-VII-1917, H. H. Rusby \& F. W. Pennell 1065 (Holotipo, NY 00090824!, isotipos, GH 00078965!, K 000533452!, PH 00018340!, US 00122505!).

= Monocardia lilacina Pennell, Proc. Acad. Nat. Sci. Philadelphia 72: 156. 1920. Bacopa lilacina (Pennell) Standl., Publ. Field Mus. Nat. Hist., Bot. Ser. 11: 174. 1936. TIPO: COLOMBIA. Meta, in forest near Villavicencio, 28-VIII-1917, F. W. Pennell 1476 (Holotipo, NY 00090825!, isotipos, GH 00078966!, K 000533449!, PH 00018341!, US 00122506 !).

Iconografias. Descole \& Borsini 1954: 133, tab. LXXVIII; Sosa et al., 2018: 17, fig. 9.

Hierbas semiacuáticas, rastreras; de 6 a $20 \mathrm{~cm}$ long., densamente pubescentes. Tallos ascendentes, híspidos-vellosos. Hojas opuestas, sésiles, ovadas, 10-12 x 8-9 mm, ápice redondeado, base redondeada, margen entero, margen y nervaduras densamente pubescentes. Flores axilares, solitarias, pedicelos, 8-20 mm long., vellosos; sin bractéolas. Cáliz con 5 sépalos, uno dorsal oval de base cordada, dos laterales ovales de base cordada y dos internos lanceolados, tricomas en el borde, base y nervaduras. Corola de $6 \mathrm{~mm}$ long., blanca o azul, internamente glabra. Estambres 4, didínamos. Ovario ovoide, estilo entero. Cápsula ovoide, ápice agudo.

Distribución geográfica y hábitat. Especie de amplia distribución, se encuentra en México, Brasil, Paraguay y Argentina, hasta 1000 msnm. Crece en 


\section{M. de las M. Sosa et al. - Bacopa (Plantaginaceae) de Paraguay y conservación}

terrenos pantanosos y en riberas de las lagunas de varios departamentos del Paraguay que abarcan las ecorregiones del Chaco Húmedo, Cerrado y el Bosque Atlántico de Alto Paraná.

Estado de conservación en Paraguay. De acuerdo a la extensión de ocurrencia (EOO), estimada en de $72,122 \mathrm{~km}^{2}$ debería ser considerada como en preocupación menor (LC), y de acuerdo al área de ocurrencia (AOO) estimada en $56 \mathrm{~km}^{2}$, como en peligro (EN). Las principales amenazas para las poblaciones son el deterioro de su hábitat por la deforestación, dando lugar a ecosistemas modificados, que se utilizan para el cultivo, sumado al uso indiscriminado de pesticidas, los cuales, transportados por las aguas de lluvia y efluentes al lago, provocan la eutrofización y contaminación. A pesar de estas amenazas, las poblaciones son muy frecuentes. Teniendo en cuenta todo lo anterior se la categoriza de forma preliminar como LC.

Material examinado. PARAGUAY. Dpto. Amambay: Estrella, camino a Arroyo la Estrella, S22 $20^{\prime}$, W56 $55^{\prime}$, 8-X-1989, Fortunato et al. 1159 (FCQ 14714); entre Bella Vista y San Carlos, cerca del río Apa, 12-I-1982, Fernández Casas \& Molero 6266 (MO); Estancia Carmen de la Sierra, 19-III1991, Soria 4405 (FCQ, MO). Dpto. Alto Paraná: Reserva Biológica Tatí Yupí, 8-IX-1987, Caballero Marmori 1273 (CTES). Dpto. Central: Areguá, orillas del Río Negro, I-1979, Mereles 181 (CTES). Dpto. Caaguazú: S2522’00”, W55 $55^{\circ} 00^{\prime}$, 1-XII1990, Zardini \& Velázquez 24680 (AS, MO); 1-XII-1990, Zardini \& Velázquez 24777 (AS, MO). Dpto. Caazapá: Tavai; propiedad Bogado, S25 10'00", W55²0'00', 5-XII-1988, Mereles 2092 (MO); ); ídem, S26 10 ’00”, W55 20'00”, 29-X-1988, Basualdo 1676 (MO); ídem, 1503-1989, Basualdo 2144 (MO); ídem, S26¹0' 00”, W55¹7'00”, 9-XII-1989, Basualdo 2741 (MO). Dpto. Canindeyú: Reserva Natural del Bosque Mbaracayú, S245', W55²5', Marín 486 (BM, CTES, PY). Dpto. Central: Nueva Italia, 26-III-1988, Kriste Ericsson \& et al. 606 (MO); Camino Nueva Italia-Carapegua, S25 $40^{\prime}$, W57²5', 21-IV-1989, Soria 3563 (FCQ 13792); Estero del Ypoá, $10 \mathrm{~km}$ SW de Nueva Italia, S2520'00", W57²8'00", 7-XII-1990, Zardini \& Salina 25015 (AS; MO). Dpto. Cordillera: Ciervo-Cuá, S2516’00”, W57¹9’00”, II-1915,
Rojas 1031 (AS, MO); San Bernardino, orillas de estero, I-1983, Mereles 142 (CTES); cercanías de San Bernardino, costa del lago Ypacaraí, VII1988, Mereles 1266 (FCQ); Nueva Colombia, S25 10'00", W57 $7^{\circ} 13^{\prime} 00^{\prime \prime}, 26-\mathrm{V}-1990$, Zardini \& Velázquez 20591 (AS; MO); ídem, S25 10'00", W57¹3'00", Zardini \& Velázquez 20927 (AS, MO); Tobatí, "Ybytú Silla", S25 $15^{\prime} 00^{\prime}$, W57 $07^{\prime} 00$ ", Zardini \& Velázquez 26568 (FCQ, MO); ídem, S25 $12^{\prime} 00^{\prime}$, W5707'00”, 23-II-1991, Zardini \& Velázquez 26607 (FCQ, MO); 1 km NE de Nueva Colombia, Arroyo Mbaéy, S2511'00", W57¹7’00", 25-VI-1992, Zardini \& Tillería 32241 (AS, MO). Dpto. Guairá: Río Yhacá, 8 km N de Tebicuary, S2540' W56²0', 16-XI-1990, Zardini 24003 (FCQ); Trayecto a San José de los Arroyos, S25 53'56,5', W56 47'13,4”, 25-V-2000, Mereles \& González Parini 7938 (CTES, FCQ); 15 km $\mathrm{N}$ of Tebicuary, S25 40'00", W56 $46^{\circ}$ '00", 16XI-1990, Zardini \& Velázquez 24086 (AS, MO). Dpto. Misiones: Santiago, Estancia "La Soledad", 3-II-1955, Pedersen 3253 (CTES, MO). Dpto. Paraguarí: Cordillera de Villarica, Hassler 6449, 8770 (MO); Pirayú, II-1983, Mereles 146 (CTES). Dpto. San Pedro: Estancia la Blanca, III-1994, Soria 6426 (FCQ).

\section{Clave para las variedades de Bacopa scabra (Benth.) Descole \& Borsini}

1. Hojas sésiles o con un pecíolo breve, con lámina ovado-lanceolada de base aguda, híspido escábridas en la superficie adaxial. Pedicelo 4-8(13) mm long., densamente híspido-escábrido. Sépalos con ápice agudo. .. B. scabra var. scabra

1'. Hojas sésiles, con lámina ovada de base redondeada, truncada o auriculada, pubérulas. Pedicelo floral de 4-20 mm long., pubérulo. Sépalos con ápice atenuado. B. scabra var. laxiflora

12. Bacopa scabra (Benth.) Descole \& Borsini var. scabra in Descole, Gen. Sp. Pl. Argent. 5: 137. 1954. Herpestis scabra Benth., Companion Bot. Mag. 2: 57. 1836. Monniera scabra (Benth.) Kuntze, Revis. Gen. Pl. 2: 463. 1891. TIPO. BRASIL. Rio Grande do Sul, J. Tweedie 177 (Lectotipo, K 000533412! designado por Souza \& Giulietti, Pesquisas Bot. 60: 40. 2009). 
= Bacopa hassleriana Chodat \& Hassler, Bull. Herb. Boissier, ser. 2, 4: 289. 1904. TIPO: PARAGUAY. Carimbatay, E. Hassler 5820 (Lectotipo G 00229876! designado por Sosa et al., Phytotaxa 336: 16. 2018, isolectotipos, BM 000098485!, G 00229875!, G 00229877!, G 00229878!, K 000533458!, NY 00067874!, P 00634488 !).

Iconografias. Descole \& Borsini 1954: 137, tabs. LXXXI, LXXXIII); Sosa et al., 2018:18, fig. 10.

Hierbas palustres, erectas, de $40-100 \mathrm{~cm}$, estrigosas. Tallo con ramificaciones superiores, suavemente estrigoso. Hojas opuestas, sésiles o con un pecíolo breve, ovado-lanceoladas, 17-32 x 4-12 $\mathrm{mm}$, ápice agudo, base aguda, margen aserrado, densamente híspidas o escábridas. Flores axilares, solitarias o 2 por axila, pedicelos 4-13 mm long., suavemente híspidos-escábridos; dos bractéolas, 2 mm long. Cáliz con 5 sépalos, uno dorsal oval de base truncada, dos laterales lanceolados de base truncada y dos internos estrechamente lanceolados, pubérulos. Corola de 5-6 mm long., lila, internamente pubescente. Estambres 4, didínamos. Ovario ovoide, estilo entero. Cápsula globosa, ápice redondeado, inserto en el cáliz.

Distribución geográfica y hábitat. Esta especie crece en América del Sur, desde Brasil hasta el nordeste de Argentina, hasta los $1000 \mathrm{msnm}$. En Paraguay se distribuye en zonas inundables de varios departamentos que pertenecen a la ecorregión del Bosque Atlántico del Alto Paraná.

Estado de conservación en Paraguay. De acuerdo a la extensión de ocurrencia (EOO), estimada en $24,800 \mathrm{~km}^{2}$, la especie debería ser considerada como casi amenazada (NT) y, de acuerdo al área de ocupación (AOO) estimada en $20 \mathrm{~km}^{2}$, esta especie debe ser considerada como en peligro (EN). Las principales amenazas incluyen la pérdida de hábitat, debido a los avances urbanos, deforestación, modificación de cursos de agua y construcción de carreteras. Además de las talas de los pequeños parches de bosques ribereños que aún persisten y la ganadería extensiva que se realizan en el Bosque Atlántico del Alto Paraná (Mereles et al., 2015). Teniendo en cuenta todo lo anterior se la categoriza de forma preliminar como EN B2ab (ii, iii).
Material examinado. PARAGUAY. Dpto. Alto Paraná: Río Alto Paraná, Fiebrig 22102 (LIL); Estancia Río Bonito, S2537’49”'W5448’50”, 26-XII-1994, Zardini \& Vera 41812 (MO, PY). Dpto. Caazapá: Tavai, S26 ${ }^{\circ} 10^{\prime}, \mathrm{W}^{\circ} 5^{\circ} 17^{\prime}, 19-\mathrm{V}-$ 1989, Soria 3940 (CTES, FCQ); Parque Nacional Caaguazú, $26^{\circ} 05^{\prime} 52^{\prime}$ 'S $055^{\circ} 26^{\prime} 35^{\prime}$ W, 24-XI1997, Zardini \& Benítez 47438 (AS, MO). Dpto. Caaguazú: localidad no indicada, 21-I-1951, Sparre \& Vervoorst 1794 (LIL). Dpto. Canindeyú: Sierras de Maracayú, S2420'47”, W5503'09”, 18981899, Hassler 5820 (BM). Dpto. Guiará: Colonia Independencia, I-1967, Schinini 1639 (CTES); ídem, 29-III-1972, Pedersen 10104 (MO); ídem, S25 $5^{\circ} 5^{\prime}$, W56 ${ }^{\circ} 13^{\prime}, 250$ msnm, 24-XII-1986, Schinini \& Bordas 25183 (CTES). Dpto. San Pedro: Colonia Guayaibí, 20 km N de San Estanislao, 26II-1968, Krapovickas et al. 14273 (CTES).

13. Bacopa scabra var. laxiflora (Benth.) V.C. Souza, in M. G. L. Wanderley et al., Fl. Fanerogâmica do Estado de São Paulo, vol. 3: 303. 2003. Herpestis laxiflora Benth. in DC., Prodr. 10: 396. 1846. Bacopa laxiflora (Benth.) Wettst. ex Edwall, Bolm. Commiss. Geogr. Estado São Paulo 13: 176. 1897. Mella laxiflora (Benth.) Pennell, Notul. Nat. Acad. Nat. Sci. Philadelphia 46:1. 1940. TIPO: BRASIL. Piauí, "Piauhy”, Oeiras, VII1841, G. Gardner 2702 (Lectotipo K000533414!, designado por Souza \& Giulietti, Pesquisas Bot. 60: 41. 2009, isolectotipo, BM 000953370!).

= Bacopa auriculata (Robinson) Greenm., Publ. Field. Mus. Nat. Hist., Bot. Ser. 2: 262. 1907. Caconapea auriculata (Robinson) Pennell, Proc. Acad. Nat. Sci. Philadelphia 72: 150. 1920. Herpestis auriculata B.L. Rob., Proc. Amer. Acad. Arts 26:172. 1891. TIPO: MEXICO. Near Guadalajara, XI-1889, C. G. Pringle 2937 (Holotipo, GH 00078556!).

= Herpestis parvula S. Moore, Trans. Linn. Soc. London, Bot., Ser. 2., 4: 406. 1895. TIPO: BRASIL. Mato Grosso, Tapirapuan, S. Moore 383 (Holotipo, BM 000953368!).

\section{Iconografia. Fig. 4.}

Hierbas palustres, erectas, de $40-80 \mathrm{~cm}$, pubérulas. Tallo con ramificaciones superiores, pubérulo. Hojas opuestas, sésiles, ovadas, 20$45 \times$ 5-10 mm, ápice agudo, base redondeada 


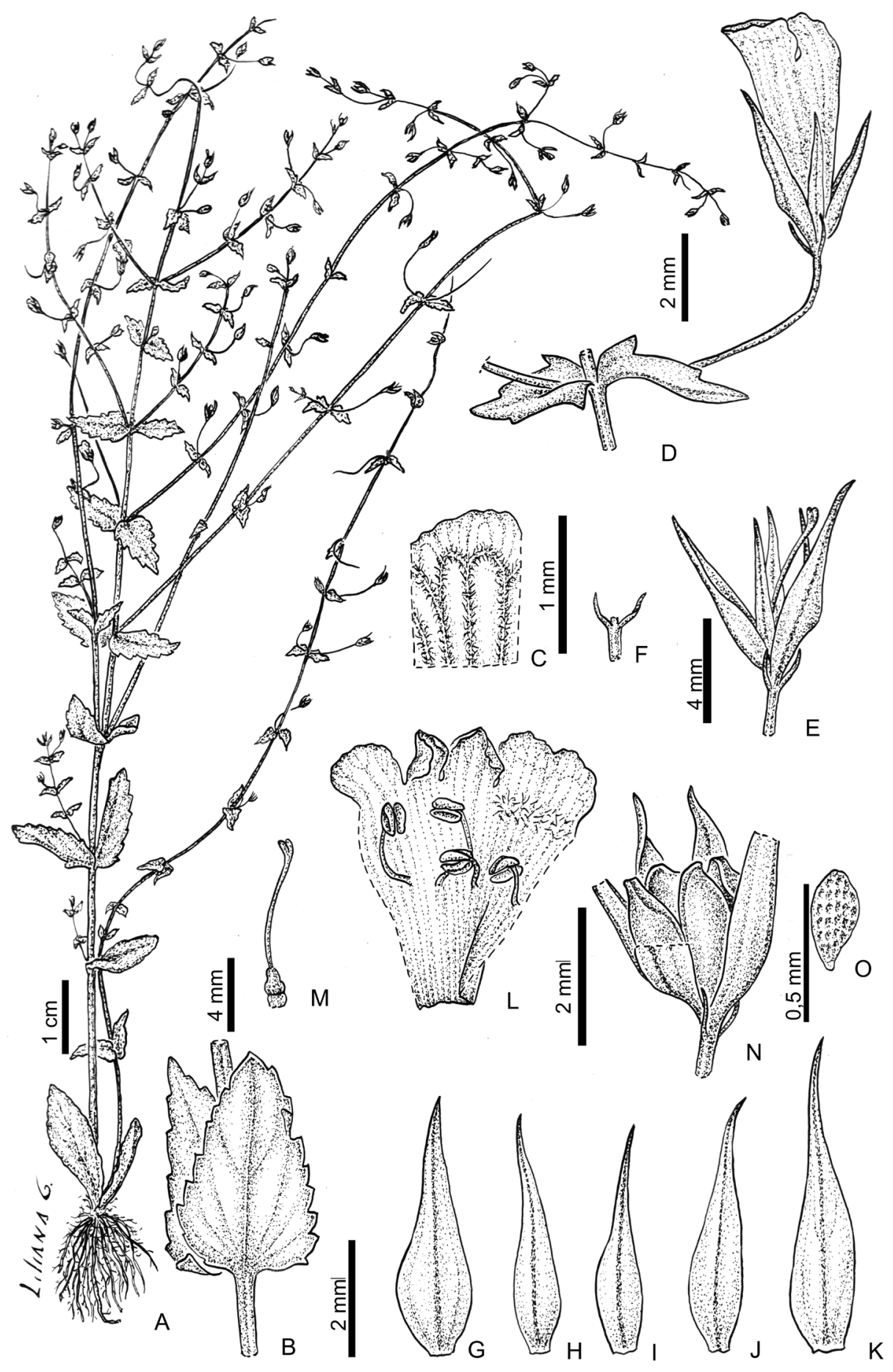

Fig. 4. Bacopa scabra var. laxiflora. A: aspecto de la planta. B: detalle del nudo con hojas. C: detalle del envés de la hoja. D: detalle del nudo con hojas opuestas y flores axilares. E: cáliz. F: bractéolas. G-J: sépalos laterales, vistas externas. H-I: sépalos internos. K: sépalo dorsal, vista externa. L: corola abierta mostrando el androceo. M: gineceo. N: cáliz con fruto. O: semilla. Ilustrado por Liliana Gómez, ejemplar Hatschbach 62751 (CTES). 
o auriculada, margen aserrado, suavemente pubérulas, sobre todo en las nervaduras. Flores axilares, solitarias o 2 por axila, pedicelos $4-20 \mathrm{~mm}$ long., pubérulos; dos bractéolas, $1 \mathrm{~mm}$ long. Cáliz con 5 sépalos, uno dorsal oval de base truncada, dos laterales lanceolados de base truncada y dos internos estrechamente lanceolados, glabros o ligeramente pubérulos. Corola de 7-8 mm long., lila, internamente pubescente. Estambres 4, didínamos. Ovario ovoide, estilo entero. Cápsula globosa, ápice redondeado, inserto en el cáliz.

Distribución geográfica y hábitat. Especie de América del Sur que crece desde México hasta Paraguay, hasta los $1000 \mathrm{msnm}$. Crece en zonas húmedas, depresiones o bordes de arroyos y lagos de las ecorregiones del Bosque Atlántico del Alto Paraná y Cerrado.

Estado de conservación en Paraguay. De acuerdo a la extensión de ocurrencia (EOO), estimada en $22,260 \mathrm{~km}^{2}$, debería ser considerada como casi amenazada (NT), y de acuerdo a su área de ocupación (AOO), estimada en $12 \mathrm{~km}^{2}$, como en peligro (EN). Este taxón fue registrado solo en tres localidades, su ocurrencia en el Bosque Atlántico del Alto Paraná está sujeta a la degradación por las actividades humanas; ya que solo el $5 \%$ del bosque original persiste. Su área de ocupación se vio reducida por la pérdida de la vegetación natural, ocurrida por la deforestación para la agricultura y facilitada por los constantes incendios que ocurren en esa área (Mereles et al., 1992, 2015). Teniendo en cuenta todo lo anterior se la categoriza de forma preliminar como EN B2ab (ii, iii, iv).

Material examinado. PARAGUAY. Dpto. Amambay: near the Rio Apa and Aquidaban, 1908-1909, Fiebrig 5194 (BM). Dpto. Alto Paraná: Itapé, S2551'00”, W54³8'00”, 20-I1930, Jorgensen 4520 (AS, MO). Dpto. Guairá: Ñeembucú, Hassler 5820 (MO); Río Yhacá, 8 km $\mathrm{N}$ of Tebicuary, S25 $40^{\prime} \mathrm{W} 56^{\circ} 40^{\prime}, 10-\mathrm{XI}-1990$, Zardini 24025 (AS, MO).

14. Bacopa serpyllifolia (Benth.) Pennell, Proc. Acad. Nat. Sci. Philadelphia 98: 98. 1946. Herpestis serpyllifolia Benth., Prodr. 10: 398. 1846. Herpestis lanigera Cham. \& Schltdl. var. serpyllifolia (Benth.) J. A. Schmidt, Fl. Bras. 8:
313. 1862. TIPO: BRASIL. Minas Gerais, São Romeo, 1840, G. Gardner 5055 (Lectotipo, K 000533480 !, designado por Souza \& Giulietti, Pesquisas Bot. 60: 63. 2009; isolectotipos, BM 000953367!, OXF 00009688V!, P 00584296!).

= Herpestis ciliata Pennell, Notul. Nat. Acad. Nat. Sci. Philadelphia 46: 2. 1940. Bacopa ciliata (Pennell) Pennell, Proc. Acad. Nat. Sci. Philadelphia 98: 98. 1946. TIPO. GUYANA. Wichabai, Rupununi River, $2^{\circ} 52^{\prime} \mathrm{N}, 25 / 26-I X-$ 1937, A. C. Smith 2281 (Holotipo, PH [no localizado]; isotipos, F 0072500F!, GH 00078562!, K000533464!, MO 503757!, NY 00068528!, S 043403 !, U 0006742!, US 00122513!).

Iconografias. Descole \& Borsini 1954: 142, tab. LXXA; Sosa et al., 2018: 20, fig. 11.

Hierbas semiacuáticas, rastreras, de $8-10 \mathrm{~cm}$, densamente pubescentes. Tallos ascendentes, vellosos. Hojas opuestas, sésiles, ovadas, raro oval-elípticas, 6-10 × 3-8 mm, ápice y base redondeados, margen entero, base, margen y nervaduras densamente pubescentes. Flores axilares, solitarias, pedicelos hasta $4-10 \mathrm{~mm}$ long.; sin bractéolas o con 2, $2 \mathrm{~mm}$ long. Cáliz con 5 sépalos, uno dorsal oval de base redondeada, dos laterales ovales de base redondeada y dos internos lanceolados, tricomas en la base y los márgenes. Corola de 7-10 mm long., azul o lila, internamente pubescente. Estambres 4, didínamos. Ovario ovoide, con un anillo de cerdas en la base, estilo entero, ápice estigmático bifurcado. Cápsula ovoide, ápice agudo.

Distribución geográfica y hábitat, Especie de Sudamérica, crece desde Venezuela hasta el norte de la Argentina en la provincia del Chaco, hasta $500 \mathrm{msnm}$. En Paraguay habita zonas inundables, charcos o pantanos temporales de las ecorregiones del Bosque Atlántico del Alto Paraná y el Chaco Húmedo.

Estado de conservación en Paraguay. De acuerdo con la extensión de ocurrencia (EOO) estimada en $1,508 \mathrm{~km}^{2}$ y al área de ocupación (AOO) estimada en $12 \mathrm{~km}^{2}$, la especie debe ser considerada como en peligro (EN). Esta especie es conocida solo para tres localidades, con poblaciones severamente fragmentadas, 


\section{M. de las M. Sosa et al. - Bacopa (Plantaginaceae) de Paraguay y conservación}

debido a la intensificación del pastoreo por ganado y la invasión de pastos exóticos facilitada por los incendios constantes (Mereles et al., 1992). Teniendo en cuenta todo lo anterior se la categoriza de forma preliminar como EN B1b (i, iii, iv) $+2 b$ (ii,iii).

Material examinado. PARAGUAY. Dpto. Canindeyú: Sierras de Maracayú, S2420'47', W55 03'09', 1898-1899, Hassler 4773 (BM). Dpto. Guairá: Villarica, 13/10/1956, Balansa 2156 (K). Dpto. San Pedro: San Pedro de Ycuamandiyú, S24 ${ }^{\circ} 19^{\prime} 17^{\prime \prime}$, W5704'39”, 26-VI2001, Zardini \& Vera 56849 (MO).

15. Bacopa stricta (Schrad.) Wettst. ex Edwall, Bol. Commiss. Geogr. Estado São Paulo: 13: 176. 1897. Herpestis stricta Schrad., Ennum. Plant. Hort. Berol. Alt. 2: 142. 1822. Caconapea stricta (Schrad.) Britton, Sc. Surv. Porto Rico \& Virgin Islands 6: 183. 1925. TIPO: Probable BRASIL. Cultivada en el Jardín Botánico de Berlín, "Horti Regii Berolinensis" (Holotipo, B, foto en $\mathrm{F}$ núm. neg. 12406!).

= Herpestis domingensis Spreng., Neue Entdeck. Pflanzenk. 3: 25. 1822. Bacopa domingensis (Spreng.) Pennell, Proc. Acad. Nat. Sci. Philadelphia 98: 92. 1946. TIPO: HAITIREPÚBLICA DOMINICANA. Isla Española, "Hab. in Hispaniola", C. Sprengel s.n. (Lectotipo BR!, designado por Souza \& Giulietti, Pesquisas Bot. 60: 22. 2009).

$=$ Herpestis polyantha Benth., Companion Bot. Mag. 2: 57. 1836. TIPO. BRASIL. Santa Catarina, J. Tweedie 176 (Lectotipo, K 000533417 ! designado por Souza \& Giulietti, Pesquisas Bot. 60: 22. 2009).

= Herpestis elongata Benth. in DC., Prodr. 10: 396. 1846. Bacopa elongata (Benth.) Pennell, Proc. Acad. Nat. Sci. Philadelphia 98: 92. 1946. TIPO. BRASIL. Goiás, São Domingos e Posse, G. Gardner 4304 (Lectotipo, K 000533415 !, designado por Souza \& Giulietti, Pesquisas Bot. 60: 22. 2009, isolectotipo, BM 000953365!).

\section{Iconografia. Fig. 5.}

Hierbas palustres, erectas, de $35-50 \mathrm{~cm}$ de alto, pubérulas. Tallo con ramificaciones superiores, pubérulo. Hojas opuestas, pecioladas, angostamente ovadas u oval-lanceoladas, $35-50 \times 7-23 \mathrm{~mm}$, ápice agudo o acuminado, base atenuada, margen aserrado, pubérulas. Flores axilares, solitarias, 2-6 por axila, pedicelos 4-20 $\mathrm{mm}$ long.; dos bractéolas, $2 \mathrm{~mm}$ long. Cáliz con 5 sépalos, un sépalo dorsal oval de base truncada, dos laterales lanceolados de base truncada y dos internos linearlanceolados, pubérulas, abundantes en bordes y nervaduras. Corola de 5-7 mm long., lila, internamente pubescente. Estambres 4, didínamos. Ovario ovoide, estilo entero. Cápsula ovoide, ápice agudo, inserto en el cáliz.

Distribución geográfica y hábitat. Especie de Sudamérica, crece desde Venezuela hasta Brasil, hasta los $1600 \mathrm{msnm}$. Habita en esteros, borde de lagunas, y zonas inundables de forma temporaria. En Paraguay esta especie se cita por primera vez para ambientes húmedos de los departamentos Central y Cordillera en la ecorregión Chaco Húmedo.

Estado de conservación en Paraguay. De acuerdo a la extensión de ocurrencia (EOO) estimada en $182,219 \mathrm{~km}^{2}$ y el área de ocupación (AOO) de $12 \mathrm{~km}^{2}$, esta especie debería ser considerada como en peligro (EN). La especie presenta un área de ocupación reducida y poco frecuente ya que se registró solo para dos localidades; en donde se observa un deterioro del hábitat, debido a a la eutrofización de los lagos y lagunas, incendios, el pastoreo de ganado, la invasión de pastos exóticos y la erosión causada por las actividades turísticas (Mereles et al., 1992, 2007). Teniendo en cuenta todo lo anterior se la categoriza de forma preliminar como EN B1b (ii, iii, iv) +2 b (ii, iii).

Material examinado. PARAGUAY. Dpto. Central: Isla Valle, 10-VI-1987, Degen 211 (CTES). Dpto. Cordillera: San Bernardino, campo estero Ciervo-Cuá, III-1915, Rojas 1294 (LIL).

16. Bacopa verticillata (Pennell \& Gleason) Pennell, Proc. Acad. Nat. Sci. Philadelphia 98: 92. 1946. Caconapea verticillata Pennell \& Gleason, Bull. Torrey Bot. Club 56: 403. 1929. TIPO. BRASIL. Roraima, south of Mount Roraima, 21IX-1927, O. Tate 72 (Holotipo, NY 00067936!, isotipo, $\mathrm{PH} 00010109$ !).

= Bacopa pedersenii Rossow, Parodiana 4: 


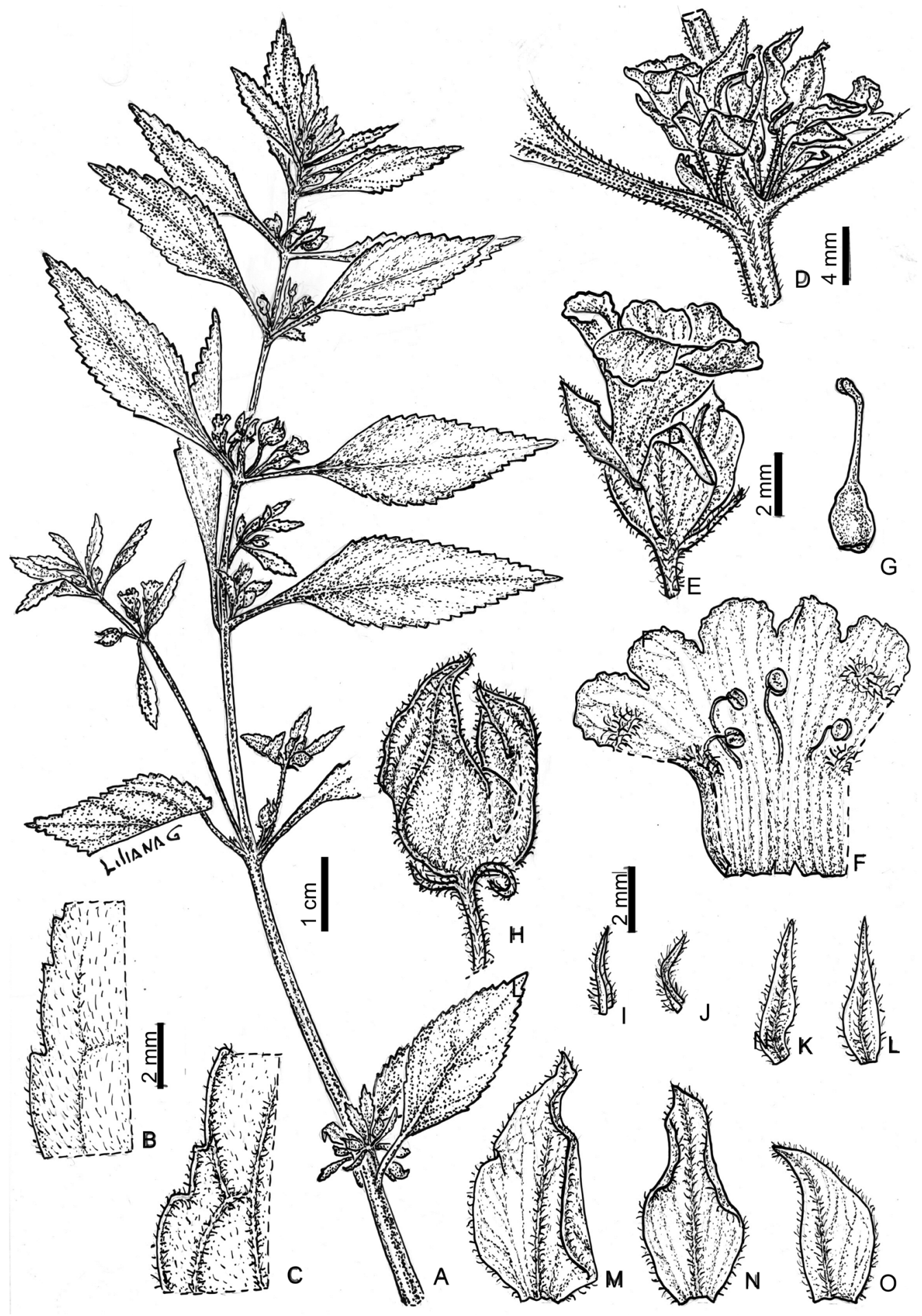

Fig. 5. Bacopa stricta. A: aspecto de la planta. B: detalle del haz de la hoja. C: detalle del envés de la hoja. D: detalle del nudo con hojas opuestas y flores axilares. E: flor. F: corola abierta mostrando el androceo. G: sépalo dorsal, vista externa. H-I: sépalos laterales, vistas externas. J-K: sépalos internos. L-M: bractéolas. N: gineceo. O: cáliz con fruto. Ilustrado por Liliana Gómez, ejemplar Degen 211 (CTES). 
176. 1986. TIPO: ARGENTINA. Corrientes, Mburucuyá, Santa Teresa, Quebrachal, Cañada Fragosa. 26-XII-1980, T. M. Pedersen 12980 (Lectotipo, CTES 0013901! designado por Sosa et al., Phytotaxa 336: 19. 2018, isolectotipos, BR 0000005423767!, CTES 0013902!, G 00356531!, S 04-3412!, UPS V-708427!).

\section{Iconografía. Sosa et al., 2018: 21, fig. 12.}

Hierbas acuáticas, en parte sumergidas; de 10-20 $\mathrm{cm}$ de alto, pubérulas. Tallos postrados, suavemente pubérulos. Hojas verticiladas, 3-5, sésiles, dimórficas, las sumergidas pinnatisectas a pinnatífidas, las aéreas pinnatífidas a ovadas, 7-16 x 1-3 mm, con base amplexicaule o auriculada, ápice agudo, margen entero, glabras. Flores axilares, solitarias, sésiles o con breve pedicelo; 2 bractéolas, 1-2 mm long. Cáliz con 5 sépalos, uno dorsal oval de base redondeada, dos laterales ovales de base redondeada y dos internos linearlanceolados, glabros, con puntos glandulares. Corola de 3-5 mm long., blanca o lila, internamente pubescente. Estambres 4, didínamos. Ovario ovoide, estilo entero, ápice estigmático bifurcado. Cápsula ovoide, ápice agudo.

Distribución geográfica y hábitat. Especie de Sudamérica que se distribuye desde las Guyanas y Venezuela hasta el nordeste de la Argentina en la provincia de Corrientes. En Paraguay se encuentra en terrenos húmedos, a veces sumergida en lagunas, esteros y lagos de la ecorregión del Bosque Atlántico del Alto Paraná.

Estado de conservación en Paraguay. De acuerdo con la extensión de ocurrencia (EOO) estimada en $6,421 \mathrm{~km}^{2}$ y al área de ocupación (AOO) estimada en $8 \mathrm{~km}^{2}$, la especie debería ser considerada en peligro crítico (CR). Solo se registró una población restringida al departamento de San Pedro. Habita áreas severamente fragmentadas y deforestadas para el cultivo, con uso indiscriminado de pesticidas, los cuales, transportados por las aguas de lluvia y efluentes a los cursos de agua, como el Lago Ypacaraí, provocan su eutrofización (Mereles et al., 1992, 2006, 2007; Fleytas, 2007). Teniendo en cuenta todo lo anterior se la categoriza de forma preliminar como CR B1ab (iii) + B2ab (iii).
Material examinado. PARAGUAY. Dpto. San Pedro: Primavera, 14-VI-1959, Woolston s.n. (SI).

\section{Conclusiones}

En relación al estado de conservación, de todas las especies del género Bacopa que crecen en Paraguay, $13(80 \%)$ cumplen con al menos un criterio bajo una categoría de amenaza. Bacopa verticillata estaría en peligro crítico (CR) y 12 especies estarían en peligro (EN). Bacopa congesta, B. dubia y B. salzmanni fueron evaluadas bajo menor preocupación (LC). La distribución restringida de las poblaciones y el declive continuo del área de ocupación de estas especies fueron las principales causas para justificar las evaluaciones. La modificación del hábitat fue causada por el establecimiento de nuevos asentamientos humanos, la deforestación para la agricultura y la ganadería, el desarrollo de la industria de la madera y el estado de eutrofización de los lagos por la acción antrópica (Fleytas 2007; Gauto et al., 2011; Mereles et al., 1992, 2007, 2015). Respecto a los ambientes en los cuales habitan, la mayoría de las especies de Bacopa (12) crecen en el Chaco Húmedo y, por otro lado, en el Bosque Atlántico del Alto Paraná se registraron 10 especies. Las especies $B$. congesta. $B$. gratioloides y $B$. salzmanni también se encuentran en el Cerrado. Finalmente $B$. monnieri es la única especie que se registró para el Chaco Seco y B. congesta y B. dubia para los Pastizales Mesopotámicos (Fig. 6).

\section{Contribución DE LOS AUTORES}

MMS y JEF diseñaron y realizaron la investigación, recolectaron e interpretaron los datos, MMS redactó el borrador del manuscrito y preparó las figuras. JEF analizó los datos geográficos, realizó la evaluación de la conservación de las especies, confeccionó los mapas de distribución y preparó las figuras. AVS consultó herbarios, analizó los resultados obtenidos y revisó el manuscrito en su versión final. Todos contribuyeron en la redacción final. 

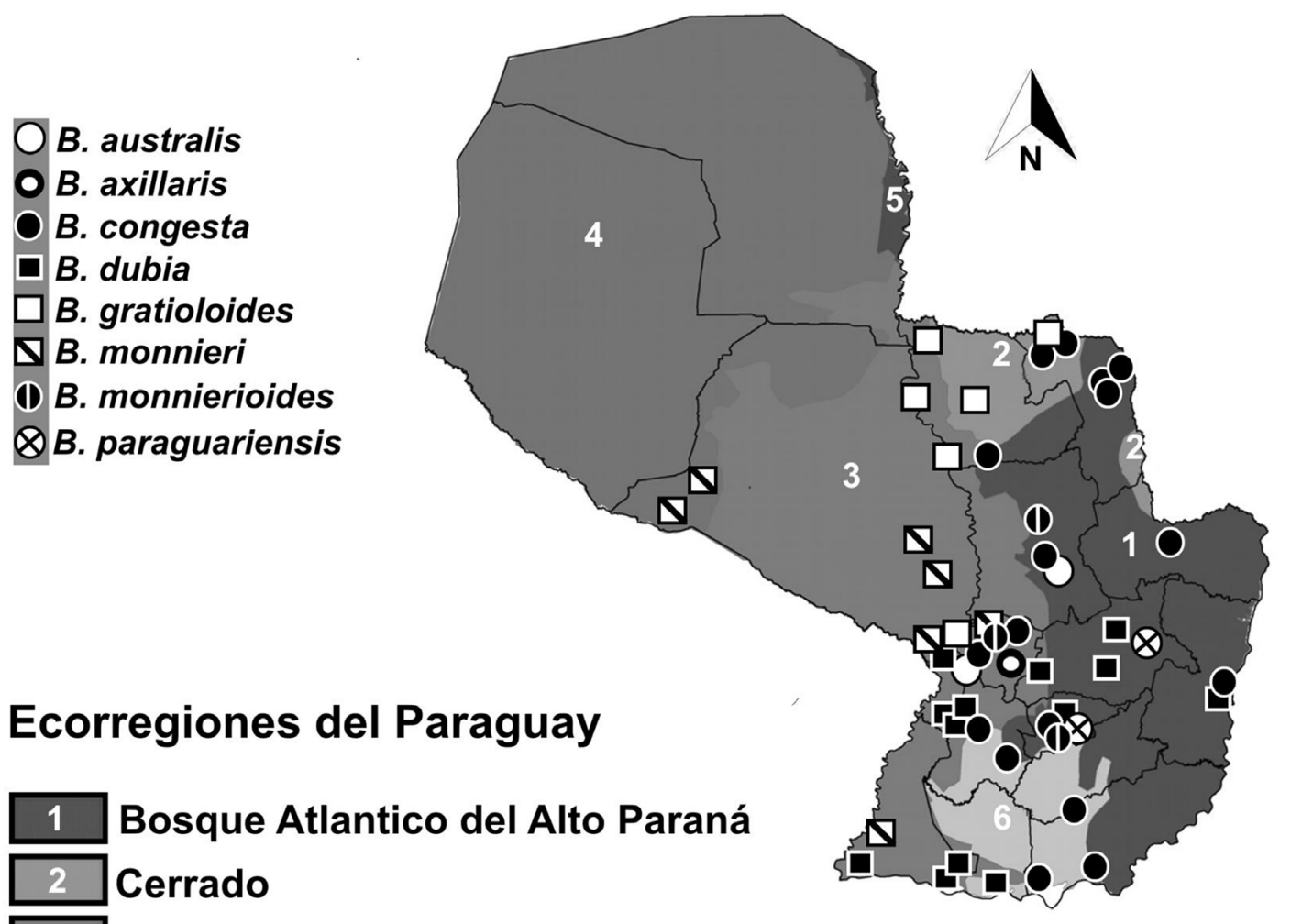

\section{Ecorregiones del Paraguay}

\section{Cerrado \\ 3 Chaco humedo \\ 4 Chaco seco \\ 5 Pantanal \\ 6 Pastizales}

1 Bosque Atlantico del Alto Paraná

B. repens

OB. rotundifolia

$\Delta B$. salzmannii

$\square$ B. scabra

$\square$ B. serpyllifolia

(1) B. stricta

OB. verticillata

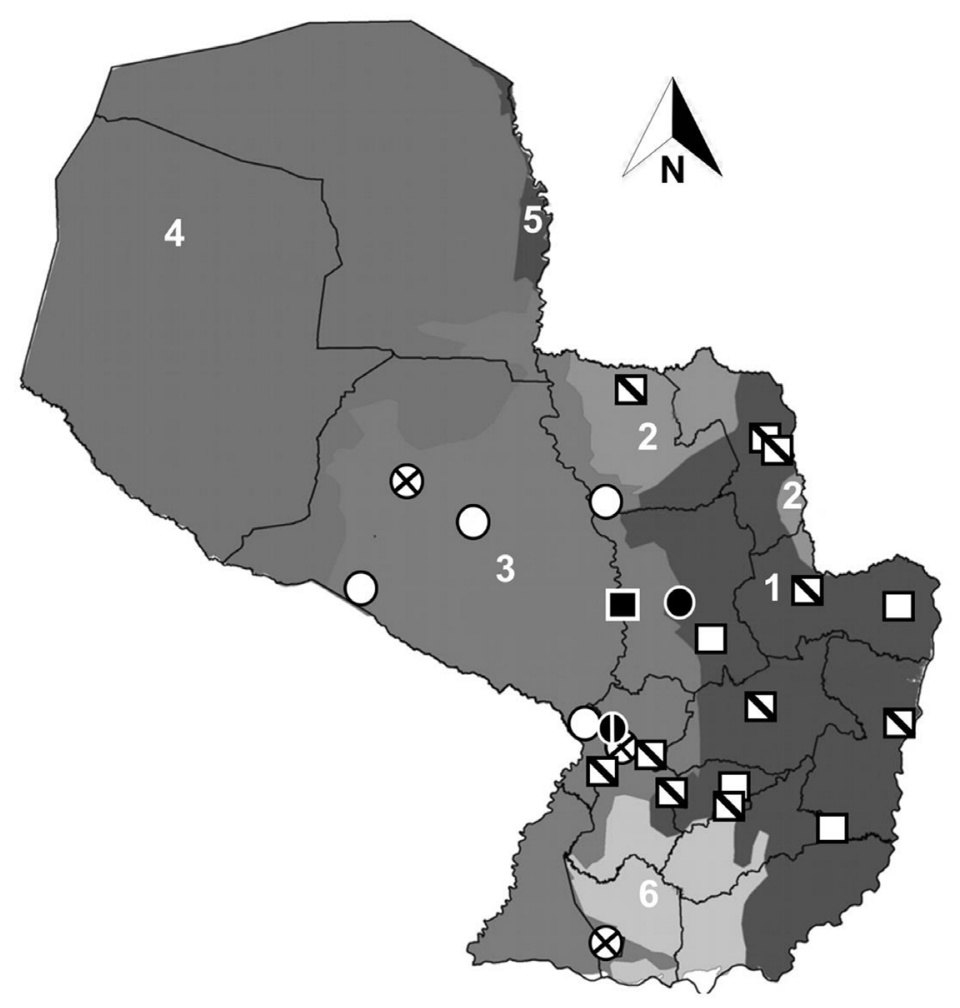

Fig. 6. Distribución de las especies de Bacopa en las ecorregiones de Paraguay. 


\section{M. de las M. Sosa et al. - Bacopa (Plantaginaceae) de Paraguay y conservación}

\section{Agradecimientos}

Un agradecimiento especial a Mirtha Liliana Gómez por las hermosas ilustraciones y a Roberto Salas por las fotografías y la ayuda en el trabajo de campo en Paraguay. Este trabajo ha recibido apoyo económico del CONICET PIP 11220150100125 y SGCyT-UNNE PI 19P005.

\section{Bibliografía}

ALBACH, D. C., H. M. MEUDT \& B. OXELMAN. 2005. Piecing together the "new" Plantaginaceae. Am. J. Bot. 92: 297-315. https://doi.org/10.3732/ajb.92.2.297

ÁVILA, I. 2018. Análisis biogeográfico del Paraguay a través de la identificación de áreas de endemismos Tesis de Maestría. Universidad Nacional de Asunción, San Lorenzo, Paraguay.

BACHMAN, S., J. MOAT, A. W. HILL, J. DE LA TORRE \& B. SCOTT. 2011. Supporting Red List threat assessments with GeoCAT: geospatial conservation assessment tool. ZooKeys 150: 117126. https://doi.org/10.3897/zookeys.150.2109

CHAROENPHON, N., N. ANANDSONGVIT, P. KOSAI, K. SIRISIDTHI, N. KANGWANRANGSAN \& W. JIRAUNGKOORSKUL. 2016. Brahmi (Bacopa monnieri): Up-to-date of memory boosting medicinal plant: A review. Indian J. Agric. Res. 50: 1-7. https://doi.org/10.18805/ijare.v50i1.8582

CHRISTENHUSZ, M. J. M. 2011. Plantaginaceae. En: DAVIDSE, G., M. SOUSA SÁNCHEZ, S. KNAPP \& F. CHIANG CABRERA (eds.), Flora mesoamericana, pp. 1-73. Missouri Botanical Garden Press, St. Louis.

CLAY, R., J. DE EGEA \& H. DEL CASTILLO. 2005. Ecorregiones de Paraguay. En: DEL CASTILLO, H., \& R. P. CLAY (eds.), Atlas de las aves de Paraguay, pp. 6-9. Asociación Guyra Paraguay, Asunción.

D'ARCY, W. G. 1979. Scrophulariaceae. Family 171. En: WOODSON, R. E., JR., R. W. SCHERY \& W. G. D'ARCY (eds.), Flora of Panama, part IX, pp. 173-272, Ann. Missouri Bot. Gard. 66. Missouri Botanical Garden Press, St. Louis. https://doi.org/10.2307/2398908

DESCOLE, H. R. \& O. H. BORSINI. 1954. Scrophulariaceae. En: DESCOLE, H. R. (ed.), Genera et Species Plantarum Argentinarum, pp. 1-167. Guillermo Kraft, Buenos Aires.
DHANASEKARAN, M., B. THARAKAN, L. A. HOLCOMB, A. R. HITT, K. A. YOUNG \& B. V. MANYAM. 2007. Neuroprotective mechanisms of ayurvedic antidementia botanical Bacopa monniera. Phytother. Res. 21: 965-969. https://doi.org/10.1002/ptr.2195

DE EGEA, J., F. MERELES, M. C. PEÑA-CHOCARRO \& G. CÉSPEDES. 2016. Checklist for the crop weeds of Paraguay. PhytoKeys 73: 13-92. https://doi.org/10.3897/phytokeys.73.10135

GAUTO, I., R. E. SPICHIGER \& F. W. STAUFFER. 2011. Diversity, distribution and conservation status assessment of Paraguayan palms (Arecaceae). Biodivers. Conserv. 20: 2705-2728. https://doi.org/10.1007/s10531-011-0100-6

FAUSTO, M. A., N. G. MACHADO, J. SOUZA NOGUEIRA \& M. S. BIUDES. 2014. Net radiation estimated by remote sensing in Cerrado areas in the Upper Paraguay River Basin. J. Appl. Rem. Sens. 8: 083541. https://doi.org/10.1117/1.JRS.8.083541

FLEYTAS, M. C. 2007. Cambios en el paisaje: evolución de la cobertura vegetal en la Región Oriental del Paraguay. En: SALAS-DUEÑAS, D. \& J. FACETTI (eds.), Biodiversidad del Paraguay: una aproximación a sus realidades, pp. 77-87. Fundación Moisés Bertoni, Asunción.

HIJMANS, R. J. 2015. DIVA-GIS, a geographic information system for the analysis of biodiversity data. Version 7.5. Disponible en: http://www.divagis.org. [Acceso: 20 octubre 2019].

IUCN STANDARDS AND PETITIONS SUBCOMMITTEE. 2017. Guidelines for using the IUCN Red List categories and criteria version 13.www.iucnredlist.org/documents/ RedListGuidelines.pdf

ITHAKA. 2020. JSTOR Global Plants [online]. Disponible en: http://plants.jstor.org

MERELES, F., R. DEGEN \& N. LOPEZ DE KOCHALCA. 1992. Humedales en el Paraguay: breve reseña de su vegetación. Amazoniana 12: 305-316.

MERELES, F. 2006. La diversidad, los usos y la conservación de las especies vegetales en los humedales del Paraguay. Rojasiana 7: 171-185.

MERELES F. 2007. La diversidad vegetal en el Paraguay. En: SALAS-DUEÑAS, D. \& J. F. FACETTI (eds.), Biodiversidad del Paraguay: Una aproximación a sus realidades, pp. 89-105. Fundación Moisés Bertoni, Asunción, Paraguay. 
MERELES, F., J. DE EGEA, G. CÉSPEDES, M. C. PEÑA-CHOCARRO \& R. D. ARRÚA. 2015. Plantas acuáticas y palustres del Paraguay, Vol. 1. Bryophyta, Pteridophyta, Angiospermae Monocotyledoneae. Facultad de Ciencias Químicas, Asunción.

NUGRAHA, I., YUNITA, R., E. G. LESTARI \& I. ARDI. 2017. Pembentukan mother plant Bacopa australis secara in-vitro dan aklimatisasi dalam aquascape air tawar. Media Akuakultur 12: 85-94. https://doi.org/10.15578/ma.12.2.2017.85-94

PENNELL F. W. 1946. Reconsideration of the BacopaHerpestis problem of the Scrophulariaceae. Proc. Acad. Nat. Sci. Philadelphia 98: 83-98.

POTT, V. J. \& A. POTT. 1997. Checklist das macrófitas aquáticas do Pantanal, Brasil. Acta Bot. Brasil. 11: 215-227.

https://doi.org/10.1590/s0102-33061997000200010

POTT, V. J., A. POTT, L. C. P LIMA, S. N. MOREIRA \& A. K. M. OLIVEIRA. 2011. Aquatic macrophyte diversity of the Pantanal wetland and upper basin. Braz. J. Biol. 71: 255-263. https://doi.org/10.1590/s1519-69842011000200004

RUSSO, A. \& F. BORRELLI. 2005. Bacopa monniera, a reputed nootropic plant: an overview. Phytomedicine 12: 305-317.

SCATIGNA, A. V., P. W. FRITSCH, V. C. SOUZA \& A. O. SIMÕES. 2018. Phylogenetic relationships and morphological evolution in the carnivorous genus Philcoxia (Gratioleae, Plantaginaceae). Syst. Bot. 43: 910-919.

https://doi.org/10.1600/036364418X697814
SOSA, M. M., P. MORONI \& N. O'LEARY. 2018. A taxonomic revision of the genus Bacopa (Gratioleae, Plantaginaceae) in Argentina. Phytotaxa 336: 1-27. https://doi.org/10.11646/phytotaxa.336.1.1

SOUZA, C. D. D. \& J. M. FELFILI. 2006. Uso de plantas medicinais na região de Alto Paraíso de Goiás, Brasil. Acta Bot. Bras. 20: 135-142. https://doi.org/10.1590/s0102-33062006000100013

SOUZA, V. C. 2001. Uma nova espécie de Bacopa Aubl. (Scrophulariaceae) da América do Sul. Acta Bot. Brasil.15: 57-61. https://doi.org/10.1590/S0102-33062001000100007

SOUZA, V. C. \& A. M. GIULIETTI. 2009. Levantamento das espécies de Scrophulariaceae sensu lato nativas do Brasil. Pesquisas Botânica 60: 7-288.

SOUZA, V. C. 2020. Bacopa. Flora do Brasil 2020. Instituto de Pesquisas Jardim Botânico do Rio de Janeiro. Disponible en: http://floradobrasil.jbrj.gov.br/reflora/ listaBrasil/. [Acceso: 20 Diciembre 2020].

THIERS, B. continuously updated. Index Herbariorum: a global directory of public herbaria and associated staff. New York Botanical Garden's Virtual Herbarium. http://sweetgum.nybg.org/science/ih. [Acceso: 6 Septiembre 2020].

VOHORA, S. B., T. KHANNA, M. ATHAR \& B. AHMED. 1997. Analgesic activity of bacosine, a new triterpene isolated from Bacopa monnieri. Fitoterapia 61: 361-365.

YUNITA, R., E. G. LESTARI \& M. MASTUR. 2018. Perbanyakan tanaman hias air Bacopa australis secara in vitro pada berbagai formulasi hormon media pertumbuhan. Media Akuakultur 13: 75-82. https://doi. org/10.15578/ma.13.2.2018.75-82 